\title{
Multi-criteria-based sub-basin prioritization and its risk assessment of erosion susceptibility in Kansai-Kumari catchment area, India
}

\author{
Raj Kumar Bhattacharya ${ }^{1} \cdot$ Nilanjana Das Chatterjee ${ }^{1} \cdot$ Kousik Das $^{1}$
}

Received: 17 July 2018 / Accepted: 12 April 2019 / Published online: 30 April 2019

(C) The Author(s) 2019

\begin{abstract}
Environmental processes are interrupted by the water action like soil erosion, mass movement as well as siltation on the dam in the undulating catchment area. Soil erosion is one of them and degraded the basin potentiality. This paper demonstrates that erosion susceptibility status in the 13 sub-basins of Kansai-Kumari catchment area has been determined depending upon its morphometric, lithology, geomorphic, land use/land cover (LULC), slope and soil characteristics used by integrated micro-watershed prioritization rank which is based on susceptible capacity under geographical information system platform. Risk assessment of soil erosion was measured by hypsometric characteristic (Hi) and denudation rate (tu) to assess the geological stage of landform and risk status for conservative practices. The result shows that SB13, 2 have a high risk (tu $>90 \mathrm{t} / \mathrm{km}^{2} /$ year) due to the presence of low priority rank of morphometric, geomorphic, slope, soil and high priority rank of lithological set-up and LULC but reached under the late mature geological stage (Hi $>0.35)$. SB3, 4, 10 have a low risk (tu $<83 \mathrm{t} / \mathrm{km}^{2} /$ year) due to the presence of high priority rank of morphometric, geology, geomorphic, slope and soil types under the mature stage of geological setting ( $\mathrm{Hi}>0.5$ ). But SB7, 8,9 have the medium risk $\left(\mathrm{tu}<85 \mathrm{t} / \mathrm{km}^{2} /\right.$ year) due to the presence of erosion-prone LULC patterns like cropland and laterite cover but having low final priority rank and old geological stage $(\mathrm{Hi}<0.35)$. Therefore, erosion susceptibility does not depend on morphometric aspects but also depends on other determinant themes at the sub-basin level.
\end{abstract}

Keywords Basin potentiality $\cdot$ Erosion susceptibility $\cdot$ Micro-watershed prioritization $\cdot$ Hypsometric characteristic . Denudation rate

\section{Introduction}

Sustainable development of natural resources and watershed management can be better understood through the analysis of drainage basin such as topography, slope, run-off characteristics, soil condition and surface water potential. The

Electronic supplementary material The online version of this article (https://doi.org/10.1007/s13201-019-0954-4) contains supplementary material, which is available to authorized users.

Raj Kumar Bhattacharya

rajgeovu10@gmail.com

Nilanjana Das Chatterjee

nilanjana_vu@mail.vidyasagar.ac.in

Kousik Das

kousik.akash@gmail.com

1 Department of Geography and Environment Management, Vidyasagar University, Midnapore, West Bengal 721102, India analysis of drainage basin plays a crucial role in preparation of watershed management with the following geomorphometric land cover parameters. Watershed management programme depends on various interrelationships like the connection between geology, geomorphology, slope, land use, soil, low lands and uplands (Chandrashekar et al. 2015). Several recent research works have been carried out in basin prioritization through the analysis of the integration of geophysical and land use and land cover patterns (Javed et al. 2009; Malik and Bhat 2014). These parameters help in determining the basin priority used by assigned knowledge-based weightage as per their relative contribution to watershed degradation (Aher et al. 2013; Rahaman et al. 2015). However, basin management programme was mainly concentrated on soil and water conservation than basin boundary demarcation (Gajbhiye et al. 2015a, b; Chandrashekar et al. 2015). In India, excessive population pressure violates the natural resources due to $16 \%$ population of world population presence on only $2.42 \%$ of the global land area. It is the fact 
that soil erosion and land degradation cover the huge land area near about 175 million hectares (66\%) of the total geographical area (Meshram and Sharma 2017). On the other hand, soil loss nearly about 5300 million tons in the entire topsoil falls under the active erosion area caused by water and wind action. They have separately estimated about 150 million hectares erosion area, whereas rest of the land degradation area increased up to 25 million hectares caused by ravine and gullies, water logging, shifting cultivation, salinity or alkalinity, etc. (Gajbhiye 2015; Meshram and Sharma 2017).

Soil erosion is an important problem of the Kangsabati basin especially in Kansai-Kumari catchment site where main six components of the topography, namely morphometric aspects, geological set-up, geomorphic landscape, slope steepness and length, soil class and land use/land cover control the movement of the soil (Mukhopadhyay 1992). Rill and gully action are predominant agents for the soil erosion in escarpment zone of Kansai-Kumari inter-fluvial site due to the presence of steep slope and indiscriminate land use patterns, whereas light texture porous sandy soil helps in generating soil erosion susceptibility or rapid sheet erosion in the upper part of this basin.

Quantitative analysis of basin characteristic mainly depends on morphometric parameters for providing three important aspects, i.e. linear, aerial and relief (Strahler 1964; Biswas et al. 1999). This is the integrated parameter with geographical information system (GIS) and soil erosion measurement using several geomorphic techniques (Chopra et al. 2005; Javed et al. 2009, 2011; Sharma et al. 2015). Morphometric parameters help in estimating the rank priority that predicts the deficit and surplus zones of soil erosion in every sub-basin (Deepika et al. 2013). Land use and land cover (LULC) change is another important integrating parameter for the estimation of basin prioritization and land degradation or deterioration of watershed status under GIS platform (Malik and Bhat 2014; Sujatha et al. 2014; Altaf et al. 2014). Ground slope and gradient of the drainage network provide the structural arrangement of three morphometric aspects, i.e. linear, aerial and relief (Clarke 1996; Malik et al. 2011). These are important parameters for the detection of indigenous geophysical parameters-based basin prioritization as well as help in effective taking step of sustainable planning and management in every sub-basin (Javed et al. 2011; Patel et al. 2012; Malik and Bhat 2014). It is noted that basin prioritization does not depend on morphometric, land use/land cover and slope but also depends on the geological structure and soil characteristic (Chauhan et al. 2016). Prioritization status is determined by the computation of compound values $(\mathrm{Cp})$ from selected parameters, and then, these values are correlated and superimposed on each and other. On the other hand, erosion susceptibility was measured by hypsometric analysis and denudation rate estimation per unit area at sub-basin level. Hypsometric analysis is used for prediction of the surface elevation and geomorphological state such as youth (in equilibrium), mature (equilibrium) and old (Monadnock) stage to assess the erosion risk assessment and structural forms in a basin (Sharma et al. 2013; Martínez-Ramírez et al. 2017), whereas denudation rate estimation is a indirect geomorphic index to assess the erosion process under the hierarchical drainage basin (Horton 1945; Strahler 1952, 1964; Avena et al. 1967; Ciccacci et al. 1980, 2003; Della Seta et al. 2007; Gioia et al. 2011). This hypothesis result predicts the correlation between the priority status of the basin and soil erosion susceptibility in every sub-basin. Therefore, all integrated theme-based prioritization depicts that high soil erosion susceptible zone was concentrated on high priority status based on basin area and vice versa (Gajbhiye et al. 2014; Chauhan et al. 2016; Meshram and Sharma 2017). Several research works have been conducted about the priority status of the basin, but there has research gap how integrated theme-based prioritization accelerated the soil erosion susceptibility.

The objective of this study is to assess the basin priority status using individually assigned weights and ranks based on order-wise potential effects of environmental degradation from geomorphometric, geology, slope, LULC and soil. Then, sub-basin-wise risk assessment of erosion susceptibility stage is determined and used by hypsometric analysis and denudation rate estimation to appropriate soil and water conservative measures in the entire upper catchment area of Kansai-Kumari basin.

\section{Study area}

Kumari River is the most important tributary of the Kangsabati which originated from the Baghmundi hill area. Two channels, one from north and north-west and another from south and south-west, join together at Kerwa and flow under the name 'Kumari'. On the other hand, Kansai River is originated from the Chota Nagpur plateau in the state of Jharkhand, India, and passes through the districts of Purulia, Bankura and Paschim Medinipur in W.B. and drains into Hooghly River. From the confluence point of view, Kumari River flows in the north-west to south-east direction over the gently undulating plains of Purulia plateau terrain and finally meets with the Kangsabati-the trunk stream at Ambikanagar with the total length of about $97 \mathrm{~km}$ (Fig. 1). According to the geographical point of view, upper part of Kangsabati basin or Kansai-Kumari catchment area is bounded by $23^{\circ} 20^{\prime} 0^{\prime \prime} \mathrm{N}$ to $22^{\circ} 55^{\prime} 0^{\prime \prime} \mathrm{N}$ latitudes and $86^{\circ} 0^{\prime} 0^{\prime \prime} \mathrm{E}$ to $86^{\circ} 40^{\prime} 0^{\prime \prime} \mathrm{E}$ longitudes. Entire catchment area covers an area of $3522 \mathrm{~km}^{2}$ and also divided this basin into 13 sub-basins. This basin falls under the undulating terrain 


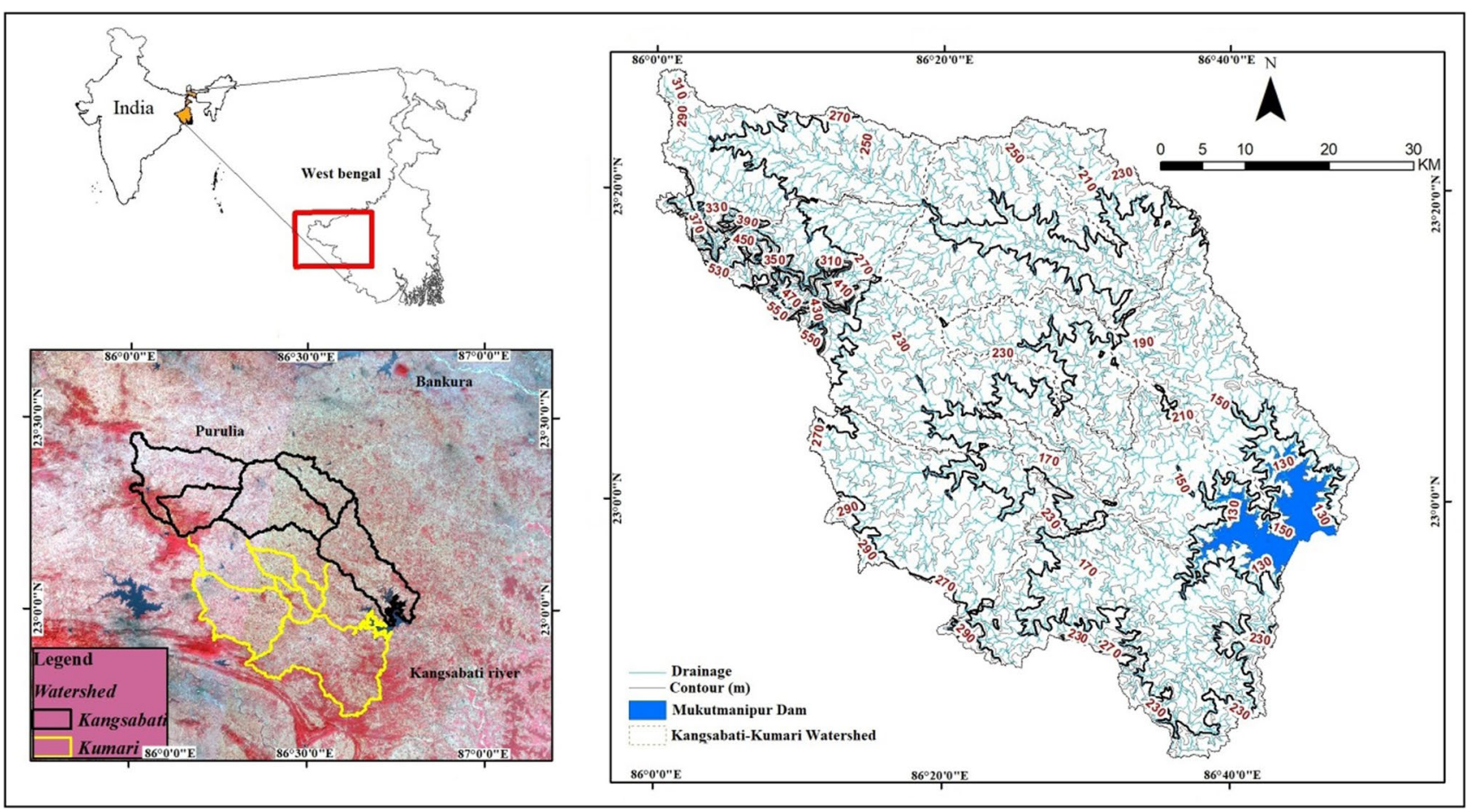

Fig. 1 Location map of Kansai-Kumari catchment area

characteristics (680 m-117 m) started from Baghmundi and Dalma marginal fringe to narrow escarpment zone. Climatic characteristic of this basin is dry except during south-west monsoon season. Rainfall occurs from 1400 to $1500 \mathrm{~mm}$ during monsoon season but annually ranges from 250 to $350 \mathrm{~mm}$, whereas highest temperature during the month of May is $43{ }^{\circ} \mathrm{C}$ and lowest temperature during the month of January is $6^{\circ} \mathrm{C}$. Soil characteristic in the entire upper catchment is light textured, shallow to moderately deep and with intense erosion susceptibility (Mukhopadhyay 1992). Land use patterns mainly forest degradation and paddy cultivation play a vital role in the acceleration of soil erosion on this steep slope land surface (Mahala 2018).

\section{Material and methodology}

\section{Data products and image processing}

The study area of Kansai-Kumari inter-fluvial basin is delineated using Survey of India (SOI) topographical sheets (No 73I/10, 11, 12, 13 of 1:50000 scale) of 1975 edition and ASTER (Advance Space bone Thermal Emission and Reflection Radiometer) DEM. These digital data sets were used for systematic analysis of various thematic map, i.e. morphometric, slope and land use/land cover (LULC) characteristics, of the river basin under proper GIS platform. Toposheet also helps in detecting threshold drainage pattern from basin outlay which is provided by ASTER DEM. DEM provided the direct execution of slope and elevation map, whereas morphometric analysis of drainage basin is executed through the preparation of hierarchical stream order based on Strahler method (1964). On the other hand, LULC and soil map generated from LANDSAT TM and West Bengal soil sheet 2 were prepared by ICAR (Table 1). All these parameters were used for delineation of the basin as well as detection of priority status into 13 sub-basins (Fig. 2).

Every single parameter of individual category like geophysical (lithology, slope, geomorphology and soil), morphometric and LULC was determined through the estimation of knowledge-based weightage value which depends on the role of soil erosion susceptibility. Priority status in each parameter has been assigned from theme-based parameters result. In the morphometric analysis of basin, three aspects, i.e. linear, areal and relief, have been calculated from the drainage layer from Kansai-Kumari inter-fluvial basin following referred methods shown in Table 2. These aspects are used for making morphometric priority rank in the selected sub-basin.

Prioritization of morphometric, geology, geomorphic, slope and soil has been assigned from the role of their susceptibility to erosion and percentage area of classified category (Patwary et al. 2009; Patel et al. 2012; Chauhan et al. 2016; Meshram and Sharma 2017). Priority of sub-basin $(\mathrm{Sb})$ is estimated from the rank of compound value $(\mathrm{Cp})$ which is ascribed to the average values of six themes derived

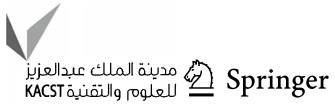


Table 1 Details of geospatial data

Fig. 2 Methodological flow chart of basin prioritization of morphometric, geology, geomorphology, LULC, slope and soil

\begin{tabular}{llllllll}
\hline Data & Type & Source & Row & Path & Sensor & Resolution $(\mathrm{m})$ & Number \\
\hline Satellite & Image & $09 / 12 / 2017$ & 139 & 45 & LANDSAT 8 & 30 & - \\
ASTER DEM & Image & $17 / 10 / 2011$ & - & - & ASTER & 1 ARC-SECOND & - \\
Toposheet & Image & SOI-1975 & - & - & - & - & 73 I/10,11,12,13 \\
Soil sheet & Image & ICAR & - & - & - & - & 2 \\
Geological & Image & GSI-1991 & - & - & - & - & 73 I \\
$\begin{array}{l}\text { Quadrangle } \\
\text { map }\end{array}$ & & & & & & & \\
\hline
\end{tabular}

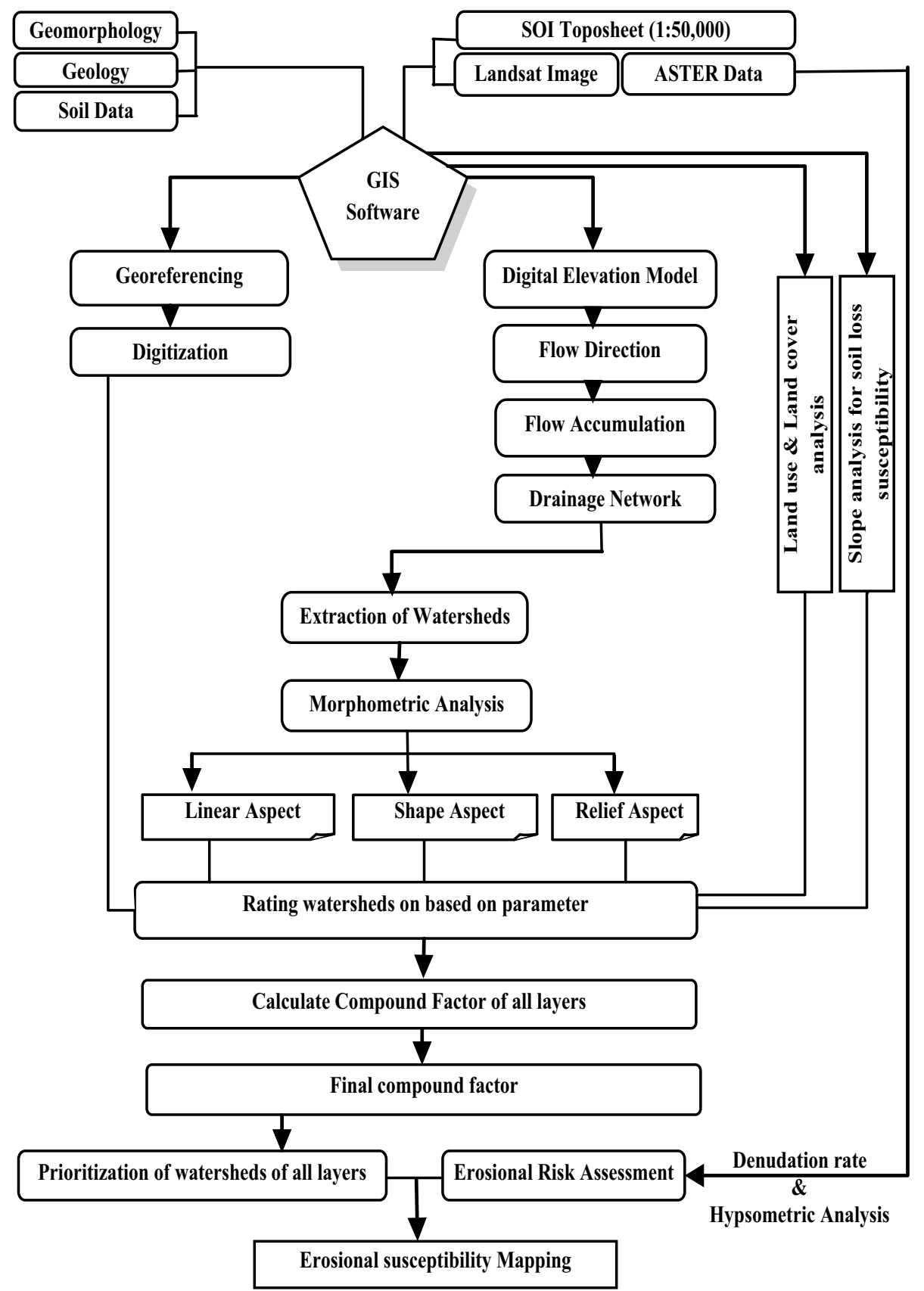


Table 2 Aspect-wise mathematical formulae used based on several morphometric parameters

\begin{tabular}{|c|c|c|c|}
\hline Aspects & Formula & Where & References \\
\hline \multicolumn{4}{|l|}{ Linear aspect } \\
\hline Basin length $(L)$ & $L=1.312 \mathrm{~A}^{0.568}$ & $\begin{array}{l}L=\text { basin length }(\mathrm{km}), A=\text { area of the basin } \\
\quad\left(\mathrm{km}^{2}\right)\end{array}$ & Nooka et al. (2005) \\
\hline Stream order $(u)$ & Hierarchical rank & & Strahler (1964) \\
\hline Mean stream length (Lsm) & $\mathrm{Lsm}=\mathrm{Lu} / \mathrm{Nu}$ & $\begin{array}{l}\mathrm{Lsm}=\text { mean stream length, } \mathrm{Lu}=\text { total stream } \\
\text { length of order ' } \mathrm{u} \text { ' } \mathrm{Nu}=\text { total no. of stream } \\
\text { segments of order ' } \mathrm{u} \text { ' }\end{array}$ & Strahler (1964) \\
\hline Stream length ratio $(\mathrm{Rl})$ & $\mathrm{RL}=\mathrm{Lu} / \mathrm{Lu}-1$ & $\begin{array}{l}\mathrm{RL}=\text { stream length ratio, } \mathrm{Lu}=\text { total stream } \\
\text { length of order ' } \mathrm{u} \text { ', } \mathrm{Lu}-1=\text { the total stream } \\
\text { length of its next lower order }\end{array}$ & Horton (1945) \\
\hline Bifurcation ratio $(\mathrm{Rb})$ & $\mathrm{Rb}=\mathrm{Nu} / \mathrm{Nu}+1$ & $\begin{array}{l}\mathrm{Rb}=\text { bifurcation ratio, } \mathrm{Nu}=\text { total no. of stream } \\
\text { segments of order ' } \mathrm{u}, \mathrm{Nu}+1=\text { number of seg- } \\
\text { ments of the next higher order }\end{array}$ & Schumm (1956) \\
\hline Mean bifurcation ratio (Rbm) & $\begin{array}{l}\text { Rbm }=\text { Average of } \\
\text { bifurcation ratios of } \\
\text { all orders }\end{array}$ & & Strahler (1964) \\
\hline \multicolumn{4}{|l|}{ Areal aspect } \\
\hline Form factor $(\mathrm{Ff})$ & $F_{\mathrm{f}}=A / L^{2}$ & $\begin{array}{c}F_{\mathrm{f}}=\text { form factor, } A=\text { area of the basin }\left(\mathrm{km}^{2}\right), \\
L=\text { basin length }(\mathrm{km})\end{array}$ & Horton $(1945,1932)$ \\
\hline Elongation ratio $(\mathrm{Re})$ & $\operatorname{Re}=1.128 \sqrt{ } A / L$ & $\begin{array}{l}\mathrm{Re}=\text { elongation ratio, } A=\text { area of the basin } \\
\quad\left(\mathrm{km}^{2}\right), L=\text { basin length }(\mathrm{km})\end{array}$ & Schumm (1956) \\
\hline Circularity ratio $(\mathrm{Rc})$ & $\mathrm{Rc}=4 \pi A / P^{2}$ & $\begin{array}{l}\mathrm{Rc}=\text { circularity ratio, } \pi=3.14, A=\text { area of the } \\
\text { basin }\left(\mathrm{km}^{2}\right), P=\text { perimeter }(\mathrm{km})\end{array}$ & Miller (1953), Strahler (1964) \\
\hline Shape factor (Bs) & $\mathrm{Bs}=L^{2} / A$ & $\begin{array}{c}\mathrm{Bs}=\text { Shape factor, } \mathrm{L}=\text { Basin length }(\mathrm{km}), \\
A=\text { Area of the basin }\left(\mathrm{km}^{2}\right)\end{array}$ & Horton (1932) \\
\hline Compactness coefficient $(\mathrm{Cc})$ & $\mathrm{Cc}=0.2821 P / A^{0.5}$ & $\begin{array}{l}\mathrm{Cc}=\text { compactness coefficient, } P=\text { perimeter } \\
(\mathrm{km}), A=\text { area of the basin }\left(\mathrm{km}^{2}\right)\end{array}$ & Gravelius (1914) \\
\hline Drainage density $(D)$ & $D=L_{\mathrm{u}} / A$ & $\begin{array}{l}D=\text { drainage density, } L_{\mathrm{u}}=\text { total stream length of } \\
\text { all orders, } A=\text { area of the basin }\left(\mathrm{km}^{2}\right)\end{array}$ & Horton $(1945,1932)$ \\
\hline Stream frequency $(\mathrm{Fs})$ & $F_{\mathrm{s}}=\sum N_{\mathrm{u}} / A$ & $\begin{array}{l}F_{\mathrm{s}}=\text { stream frequency, } \sum N_{\mathrm{u}}=\text { total no. of } \\
\text { streams of all orders, } A=\text { area of the basin } \\
\left(\mathrm{km}^{2}\right)\end{array}$ & Horton $(1945,1932)$ \\
\hline Drainage texture (Ts) & $\mathrm{Ts}=D_{\mathrm{d}} * F_{\mathrm{s}}$ & $\begin{array}{l}T=\text { drainage texture, } D_{\mathrm{d}}=\text { drainage density, } \\
F_{\mathrm{s}}=\text { stream frequency }\end{array}$ & Horton (1945) \\
\hline Constant of channel maintenance $(C)$ & $C=1 / D_{\mathrm{d}}$ & $\begin{array}{l}C=\text { constant of channel maintenance, } \\
D_{\mathrm{d}}=\text { drainage density }\end{array}$ & Schumm (1956) \\
\hline Length of overland flow (Lo) & $L_{\mathrm{o}}=1 / 2 D_{\mathrm{d}}$ & $\begin{array}{l}\mathrm{L}_{\mathrm{o}}=\text { length of overland flow, } D_{\mathrm{d}}=\text { drainage } \\
\text { density }\end{array}$ & Horton (1945) \\
\hline \multicolumn{4}{|l|}{ Relief aspect } \\
\hline Basin relief $(R)$ & $R=H-h$ & $\begin{array}{l}R=\text { basin relief, } H=\text { maximum elevation in } \\
\text { meter, } h=\text { minimum elevation in meter }\end{array}$ & Schumm and Hadley (1961) \\
\hline Relief ratio $\left(R_{r}\right)$ & $R_{r}=R / L$ & $\begin{array}{l}\mathrm{Rr}=\text { relief ratio, } R=\text { basin relief, } L=\text { longest } \\
\text { axis in kilometre }\end{array}$ & Schumm (1956) \\
\hline Ruggedness number (Rn) & $R n=\left(R \times D_{\mathrm{d}}\right) / \mathrm{K}$ & $\begin{array}{l}R n=\text { ruggedness number, } R=\text { basin relief, } \\
D_{\mathrm{d}}=\text { drainage density } \\
K=\mathrm{A} \text { conversion constant } 1000 \text { when relative } \\
\text { relief is expressed in meter and drainage } \\
\text { density in kilometre/square kilometre }\end{array}$ & Schumm (1956) \\
\hline Gradient ratio (Gr) & $\mathrm{Gr}=(a-b) / L$ & $\begin{aligned} & \mathrm{Gr}=\text { gradient ratio, } a=\text { elevation at source, } \\
& b=\text { elevation at mouth, } L=\text { longest axis in } \\
& \text { kilometre }\end{aligned}$ & Sreedevi et al. (2005) \\
\hline
\end{tabular}

from 13 sub-basins. Rank 1 is taken from highest values of final value, and next rank is rated by the second highest value of this parameter (Patel et al. 2012).
Geological formation, geomorphic set up, land use/land cover, slope and soil in each sub-basin have been assigned ranking order as giving rank ' 1 ' of highest percentage 
area of high erosion susceptibility and next rank assigned from second highest sub-basin and so on, whereas lowest percentage area of low erosion susceptibility in an individual sub-basin has been ranked ' 1 ', second lowest value as given rank ' 2 ' and so on (Chauhan et al. 2016). Ranking order of geological set-up has been assigned from the highest percentage area of Chotanagpur granite gneiss, Dolma volcanic, epidiorite, hornblende schist, garnetiferous sillimanite, granite gneiss, hornblende schist, Mahadeva formation red, oxidised sand, silt, clay, quartz biotite granite gneiss, Rajmahal Trap Basalt for highest erosovity, while ranking order has been assigned from the lowest percentage area of alluvium formation as giving rank ' 1 ', second lowest value as giving rank ' 2 ' and so on for lowest erosovity (Jasrotia et al. 2002; Patwary et al. 2009; Patel et al. 2012). Ranking order of geomorphic set-up has been assigned from the highest percentage area of buried pediments with lateritic capping, highly gullied land, inter-hill valley, pediplain, residual hills and rocky outcrop for highest erosovity, while flood plain deposits and valley fill deposits have been assigned rank from lowest percentage area as giving rank like geological setup (Jasrotia et al. 2002; Patwary et al. 2009; Gioia et al. 2011). Ranking order of LULC has been assigned from the highest percentage area of cropland, laterite, water body and settlement as giving rank ' 1 ' and so on for highest erosovity, while the lowest percentage of dense forest and open forest in each sub-basin has been given rank ' 1 ' and next lowest value as rank ' 2 ' and so on for low erosion susceptibility (Altaf et al. 2014; Perovic et al. 2018). Ranking order of slope has been assigned from the highest percentage area of very steep slope $\left(>15^{\circ}\right)$, steep slope $\left(5^{\circ}-10^{\circ}\right)$, moderate slope $\left(5^{\circ}-10^{\circ}\right)$ for high erosion susceptibility, while lowest percentage area under gentle slope $\left(<5^{\circ}\right)$ in each sub-basin has been giving rank ' 1 ', second lowest value as giving rank ' 2 ' and so on for low erosion (Jasrotia et al. 2002; Patwary et al. 2009; Farhan and Anaba 2016). Ranking order of soil has been assigned from the highest percentage area of Fine Loamy-Coarse Loamy; Gravelly Loam; Gravelly Loam-Loam; Loamy-Skeletal, Lethic Ustorthents; Loamy, Lethic Haplustaifs, while lowest percentage area of Fine, Fine Loamy and Fine Loamy, Type Haplustafs in each sub-basin has been giving rank ' 1 ' like other parameters (Sahaar 2013; Ganasri and Ramesh 2016).

$\mathrm{Cp}$ is computed by adding up all the ranks of selected themes, and then, the addition of all ranks in each sub-basin is to be divided by the number of all aspects in six parameters. So, the lowest compound factor is taking as priority ' 1 ' (highest rank) of sub-basin and next successive value has been taking as 2 and so forth. All the Cp value in each theme has been classified into three classes, i.e. high, medium and low. Higher priority class is associated with a lower composite score, while lowest priority class is concentrated with the highest composite score. Therefore, final priority status and the composite score have been established as a positive relation following equation (Chauhan et al. 2016).

$\mathrm{Cp}=1 / n \sum_{i=1}^{n} R$

where $\mathrm{Cp}$ means the compound value in every sub-basin, $R$ means the assigned rank of a specific parameter in every sub-basin and $\mathrm{n}$ means the number of following parameters.

\section{Erosion risk assessment}

\section{Hypsometric curve and integral}

The hypsometric analysis is determined by the curve generation and integral value extraction to access the stages of development of the watershed. The hypsometric curve is prepared from ASTER DEM obtaining through GLCF (Global Land Cover Facility), USA, during 2014 under GIS platform. Basin area and relief or elevation are extracted from georeferenced DEM used by spatial analyst tools of ArcGIS software to find out hypsometric value through the following equation (Strahler 1952).

$\mathrm{Hc}=\left(\frac{a}{A}\right) /\left(\frac{h}{H}\right)$

where $a / A$ means relative area and $h / H$ means relative elevation. Then, this curve is prepared by obtaining plotting value from normalised cumulative distribution of area or $a / A$ (X-axis) and normalised elevation or $h / H$ ( $Y$-axis) with the ranging scale of $0-1$ (Kaliraj et al. 2015).

On the other hand, hypsometric integral (HI) is derived from the hypsometric curve used by elevation-relief ratio method (Pike and Wilson 1971; Meshram and Sharma 2017) following equation

$\mathrm{HI}=\frac{E_{\text {mean }}-E_{\text {min }}}{E_{\text {max }}-E_{\text {min }}}$

where HI denotes elevation-relief ratio or hypsometric integral, $E_{\text {mean }}$ refers mean elevation of a watershed obtaining from identified contour demarcating area, $E_{\max }$ and $E_{\min }$ refer maximum and minimum elevation from this identified contour area.

\section{Denudation rate measurement}

Denudation rate $(\mathrm{Tu})$ is estimated by the determination of hierarchical anomaly number $(\mathrm{Ga})$, hierarchical anomaly density (ga), hierarchical anomaly index $(\Delta a)$ and drainage 
density $(D)$ to assess the erosion risk assessment (Ciccacci et al. 1980; Tokunaga 2000; Della Seta et al. 2007; Gioia et al. 2011; Bahrami 2013). Hierarchical anomaly number estimated to getting a minimum number of each stream order is based on Eq. 4 (Avena et al. 1967).

$\mathrm{Ga}=$ Number of stream order I which make the drainage network perfectly hierarchized

Then, hierarchical anomaly density (ga) is estimated by hierarchical anomaly number and basin area to getting tree shape structural drainage network based on Avena et al. 1967 formula.

$\mathrm{ga}=\mathrm{Ga} / A$

where Ga means hierarchical anomaly number and $A$ is the basin area

Hierarchical anomaly index $(\Delta a)$ is obtained from hierarchical anomaly number and actual number of stream order I to getting ratio of hierarchical anomaly density (ga) based on Eq. 6 (Avena et al. 1967).

$\Delta a=\mathrm{Ga} / N 1$

where Ga means hierarchical anomaly number and N1 means actual number of stream order I. Drainage density $(D)$ is measured by computation of areal extent of stream network and average length of stream in a drainage area to getting the role of denudation intensity shown in Table 2 (Horton 1945).

Finally, sub-basin-wise denudation rate $(\mathrm{Tu})$ rate is estimated by the following empirical equation no. 7 (Ciccacci et al. 1980, 2003).

$\log \mathrm{Tu}=1.44780+0.32619 D+0.10247 \Delta a($ if $D \leq 6)$
Denudation rate is estimated denudation power as well as amount of suspended sediment yield $\left(\mathrm{t} / \mathrm{km}^{2} /\right.$ year) and its transport as suspension mode per unit catchment area (Kaliraj et al. 2015).

\section{Results and discussion}

\section{Morphometric analysis}

Morphometric analysis of Kansai-Kumari inter-fluvial basin including 13 sub-basins (SBs) has three major aspects, i.e. (1) linear - stream order $(u)$, stream length $(\mathrm{Lu})$, basin length $(L)$, stream length ratio $(\mathrm{Rl})$, bifurcation ratio $(\mathrm{Rb}),(2)$ areal—drainage density $(D)$, stream frequency $(\mathrm{Fs})$, drainage texture (Ts), form factor (Ff), elongation ratio $(\mathrm{Re})$, circularity ratio (Rc) and shape factor (Bs), and (3) relief-basin relief $(R)$, relief ratio $(\mathrm{Rr})$, ruggedness number $(\mathrm{Rn})$ and gradient Ratio (Gr). All of these aspects were calculated from the respective equations as explained in Table 2. Results have been detailed analysis in supplementary section and are revealed in Tables 3, 4 .

\section{Prioritization on the basis of morphometric analysis}

Three morphometric aspects like linear, areal and relief have been studied for prioritization of micro-watershed, and they are contributed for the demarcation of erosion susceptible risk assessment (Biswas et al. 1999; Sujatha et al. 2014; Malik and Bhat 2014). Linear and relief parameters have a positive relationship with the erosion susceptibility, whereas aerial parameters have an inverse relationship with erodibility (Nooka et al. 2005; Chauhan et al. 2016). Priority class has been assigned from the compound value (Cp) which is

Table 3 Computed linear parameters of 13 sub-basins in Kansai-Kumari inter-fluvial site

\begin{tabular}{|c|c|c|c|c|c|c|c|c|c|c|c|c|c|c|c|c|}
\hline \multirow[t]{2}{*}{ River } & \multirow[t]{2}{*}{ SB } & \multirow[t]{2}{*}{ Basin area } & \multirow[t]{2}{*}{ Perimeter } & \multirow[t]{2}{*}{ Length } & \multicolumn{6}{|c|}{ Stream order ' $U$ ' } & \multicolumn{6}{|c|}{ Stream length $(\mathrm{Lu})$} \\
\hline & & & & & $1 \mathrm{st}$ & 2 nd & $3 \mathrm{rd}$ & 4th & 5 th & 6 th & $1 \mathrm{st}$ & 2nd & $3 \mathrm{rd}$ & 4th & 5 th & 6th \\
\hline Kansai & 1 & 399 & 205 & 39 & 237 & 49 & 12 & 1 & & & 227 & 110.3 & 65.6 & 34 & & \\
\hline Kansai & 2 & 200 & 108 & 27 & 115 & 23 & 2 & 1 & 1 & & 109 & 64.36 & 32.2 & 11 & 17.5 & \\
\hline Kansai & 3 & 432 & 171 & 41 & 246 & 55 & 11 & 2 & 1 & & 218 & 129.2 & 46.2 & 11 & 40 & \\
\hline Kansai & 4 & 174 & 124 & 25 & 111 & 24 & 4 & 1 & & & 82.8 & 41.8 & 30 & 18 & & \\
\hline Kansai & 5 & 390 & 228 & 39 & 257 & 59 & 13 & 2 & 1 & & 201 & 110.7 & 43.2 & 6.2 & 38.7 & \\
\hline Kumari & 6 & 292 & 135 & 33 & 180 & 41 & 10 & 2 & 1 & & 155 & 87.1 & 38.6 & 23 & 14.6 & \\
\hline Kumari & 7 & 390 & 153 & 39 & 239 & 51 & 11 & 4 & 2 & 1 & 207 & 107.1 & 45.4 & 36 & 15.9 & 2.873 \\
\hline Kumari & 8 & 68.9 & 60.2 & 15 & 45 & 11 & 2 & 1 & 1 & 1 & 36.5 & 19.1 & 5.58 & 3.4 & 0.96 & 9.222 \\
\hline Kumari & 9 & 85.5 & 78.7 & 16 & 52 & 9 & 2 & 1 & & & 39.7 & 24.82 & 14.3 & 6.7 & & \\
\hline Kumari & 10 & 54 & 55.3 & 13 & 31 & 6 & 1 & & & 1 & 25.7 & 18.84 & 1.5 & & & 11.24 \\
\hline Kumari & 11 & 192 & 130 & 26 & 113 & 27 & 6 & 1 & & & 105 & 50.45 & 21.1 & 26 & & \\
\hline Kumari & 12 & 207 & 130 & 27 & 140 & 34 & 6 & 1 & & 1 & 114 & 48.06 & 32 & 0.4 & & 21.45 \\
\hline Kumari & 13 & 636 & 204 & 51 & 551 & 122 & 30 & 5 & 2 & 1 & 421 & 175.7 & 114 & 36 & 34.1 & 3.045 \\
\hline
\end{tabular}


Table 4 Morphometric parameters of 13 sub-basins in Kansai-Kumari inter-fluvial site

\begin{tabular}{lllllllllllllll}
\hline SB & Rl & Rbm & Fs & Dd & T & C & Lo & Rn & Gr & Ff & Re & Rc & Bs & Cc \\
\hline 1 & 0.321 & 4.184 & 0.749 & 1.095 & 0.82 & 0.91 & 0.55 & 0.425 & 0.006 & 0.26 & 0.57 & 0.119 & 3.8896 & 2.893 \\
2 & 0.596 & 3.9 & 0.708 & 1.17 & 0.829 & 0.85 & 0.58 & 0.475 & 0.01 & 0.28 & 0.6 & 0.215 & 3.5417 & 2.155 \\
3 & 0.959 & 3.395 & 0.729 & 1.027 & 0.749 & 0.97 & 0.51 & 0.132 & 0.003 & 0.25 & 0.57 & 0.185 & 3.9317 & 2.324 \\
4 & 0.364 & 2.925 & 0.803 & 0.991 & 0.796 & 1.01 & 0.5 & 0.105 & 0.002 & 0.29 & 0.61 & 0.143 & 3.4748 & 2.648 \\
5 & 1.461 & 3.479 & 0.85 & 1.024 & 0.871 & 0.98 & 0.51 & 0.15 & 0.002 & 0.26 & 0.57 & 0.095 & 3.8777 & 3.251 \\
6 & 0.447 & 3.098 & 0.801 & 1.089 & 0.873 & 0.92 & 0.54 & 0.5 & 0.008 & 0.27 & 0.58 & 0.202 & 3.7277 & 2.222 \\
7 & 0.472 & 3.215 & 0.789 & 1.061 & 0.838 & 0.94 & 0.53 & 0.415 & 0.003 & 0.26 & 0.57 & 0.209 & 3.8777 & 2.185 \\
8 & 2.254 & 2.718 & 0.886 & 1.086 & 0.962 & 0.92 & 0.54 & 0.155 & 0.003 & 0.33 & 0.64 & 0.239 & 3.0626 & 2.046 \\
9 & 0.334 & 2.456 & 0.749 & 1 & 0.749 & 1 & 0.5 & 0.113 & 0.004 & 0.32 & 0.64 & 0.173 & 3.1541 & 2.401 \\
10 & 0.163 & 2.233 & 0.722 & 1.06 & 0.765 & 0.94 & 0.53 & 0.095 & 0.004 & 0.34 & 0.66 & 0.222 & 2.9634 & 2.121 \\
11 & 0.427 & 2.937 & 0.766 & 1.056 & 0.809 & 0.95 & 0.53 & 0.149 & 0.003 & 0.28 & 0.6 & 0.143 & 3.5206 & 2.646 \\
12 & 0.221 & 3.157 & 0.879 & 1.042 & 0.916 & 0.96 & 0.52 & 0.146 & 0.004 & 0.28 & 0.6 & 0.153 & 3.557 & 2.557 \\
13 & 0.483 & 3.817 & 1.117 & 1.231 & 1.376 & 0.81 & 0.62 & 0.44 & 0.006 & 0.24 & 0.55 & 0.191 & 4.1442 & 2.285
\end{tabular}

computed by the summing up of all the ranks value of linear, aerial and relief parameters and then dividing by parameters number in every sub-basin (Chauhan et al. 2016). First priority rank has to give from the least value of $\mathrm{Cp}$ and so on based on erosion risk assessment of morphometric parameters (Patel et al. 2012). Final priority class is divided into three classes, i.e. high, medium and low. SB1, 6, 5, 12, 13 fall under high priority class due to the presence of least $\mathrm{Cp}$ value ranging from 2.62 to 5.17, and SB4, 8, 10, 9 fall under low priority class due to the presence of high $\mathrm{Cp}$ value ranging from 6.1 to 9.1. Rest of the sub-basin in the study area reached medium priority class due to the presence of average Cp value of 5-6 as shown in Table 5 (Fig. 3b).

\section{Geological set-up and its prioritization}

Geological structure and formation influences on erosion susceptibility in a basin (Jasrotia et al. 2002; Patel et al. 2012; Chauhan et al. 2016). Lithological structure is consisted of 11 rock structures such as Rajmahal Trap Basalt $\left(129 \mathrm{~km}^{2}\right)$; quartz biotite granite gneiss $\left(2.63 \mathrm{~km}^{2}\right)$; oxidised sand, silt, clay $\left(34.55 \mathrm{~km}^{2}\right)$; Mahadeva formation red sandstone, red clay $\left(3.56 \mathrm{~km}^{2}\right)$; hornblende schist $\left(154.83 \mathrm{~km}^{2}\right)$; granite gneiss $\left(1877 \mathrm{~km}^{2}\right)$; garnetiferous sillimanite biotite schist $\left(69.94 \mathrm{~km}^{2}\right)$; epidiorite, hornblende schist $\left(987.13 \mathrm{~km}^{2}\right)$; Dolma volcanic $\left(0.82 \mathrm{~km}^{2}\right)$; Chotanagpur Granite Gneiss Complex $\left(3.48 \mathrm{~km}^{2}\right)$; and alluvium $\left(257.16 \mathrm{~km}^{2}\right)$ in the entire Kansai-Kumari reservoir catchment area during Proterozoic to upper Jurassic period. Most of the sub-basin area covers under granite gneiss geological structure (53\%), whereas oxidised sand, silt, clay has situated only SB13 within least amount $(0.023 \%)$ as shown in Table 5. Sub-basin-wise, most of the lithological structure is granite gneiss in SB1 $\left(292 \mathrm{~km}^{2}\right)$ and Mahadeva formation red sandstone, red clay in SB13 $\left(472 \mathrm{~km}^{2}\right)$, while least amount of structure is quartz biotite granite gneiss $\left(0.43 \mathrm{~km}^{2}\right)$ was concentrated in SB3 as shown in Table 6 (Fig. 4a).
Table 5 Morphometric-based assigned ranking and compound value in Kansai-Kumari interfluvial site

\begin{tabular}{rrrrrrrrrrrrrrrr}
\hline SB & Rl & Dd & Fs & Rbm & \multicolumn{1}{c}{ T } & Lo & Re & Rc & Ff & Cc & Gr & Bs & Rn & Cp & Priority \\
\hline 1 & 11 & 3 & 8 & 1 & 7 & 3 & 2 & 2 & 3 & 2 & 3 & 3 & 4 & 4 & 12 \\
2 & 4 & 2 & 11 & 2 & 6 & 2 & 4 & 9 & 7 & 10 & 1 & 7 & 2 & 5.154 & 9 \\
3 & 3 & 7 & 9 & 5 & 11 & 7 & 2 & 6 & 2 & 6 & 5 & 2 & 7 & 5.538 & 6 \\
4 & 9 & 10 & 5 & 9 & 9 & 8 & 5 & 3 & 9 & 3 & 6 & 9 & 8 & 7.154 & 3 \\
5 & 2 & 8 & 4 & 4 & 4 & 7 & 2 & 1 & 4 & 1 & 6 & 4 & 6 & 4.077 & 11 \\
6 & 7 & 4 & 5 & 8 & 4 & 4 & 3 & 7 & 5 & 8 & 2 & 5 & 1 & 4.846 & 10 \\
7 & 6 & 5 & 6 & 6 & 5 & 5 & 2 & 8 & 4 & 9 & 5 & 4 & 4 & 5.308 & 8 \\
8 & 1 & 4 & 2 & 10 & 2 & 4 & 6 & 10 & 11 & 12 & 5 & 11 & 5 & 6.385 & 4 \\
9 & 10 & 9 & 8 & 11 & 11 & 8 & 6 & 5 & 10 & 5 & 4 & 10 & 8 & 8.077 & 2 \\
10 & 13 & 5 & 10 & 12 & 10 & 5 & 7 & 9 & 12 & 11 & 4 & 12 & 9 & 9.154 & 1 \\
11 & 8 & 5 & 7 & 9 & 8 & 5 & 4 & 3 & 8 & 3 & 5 & 8 & 6 & 6.077 & 5 \\
12 & 12 & 6 & 3 & 7 & 3 & 6 & 4 & 4 & 6 & 4 & 4 & 6 & 6 & 5.462 & 7 \\
13 & 5 & 1 & 1 & 3 & 1 & 1 & 1 & 6 & 1 & 7 & 3 & 1 & 3 & 2.615 & 13 \\
\hline
\end{tabular}



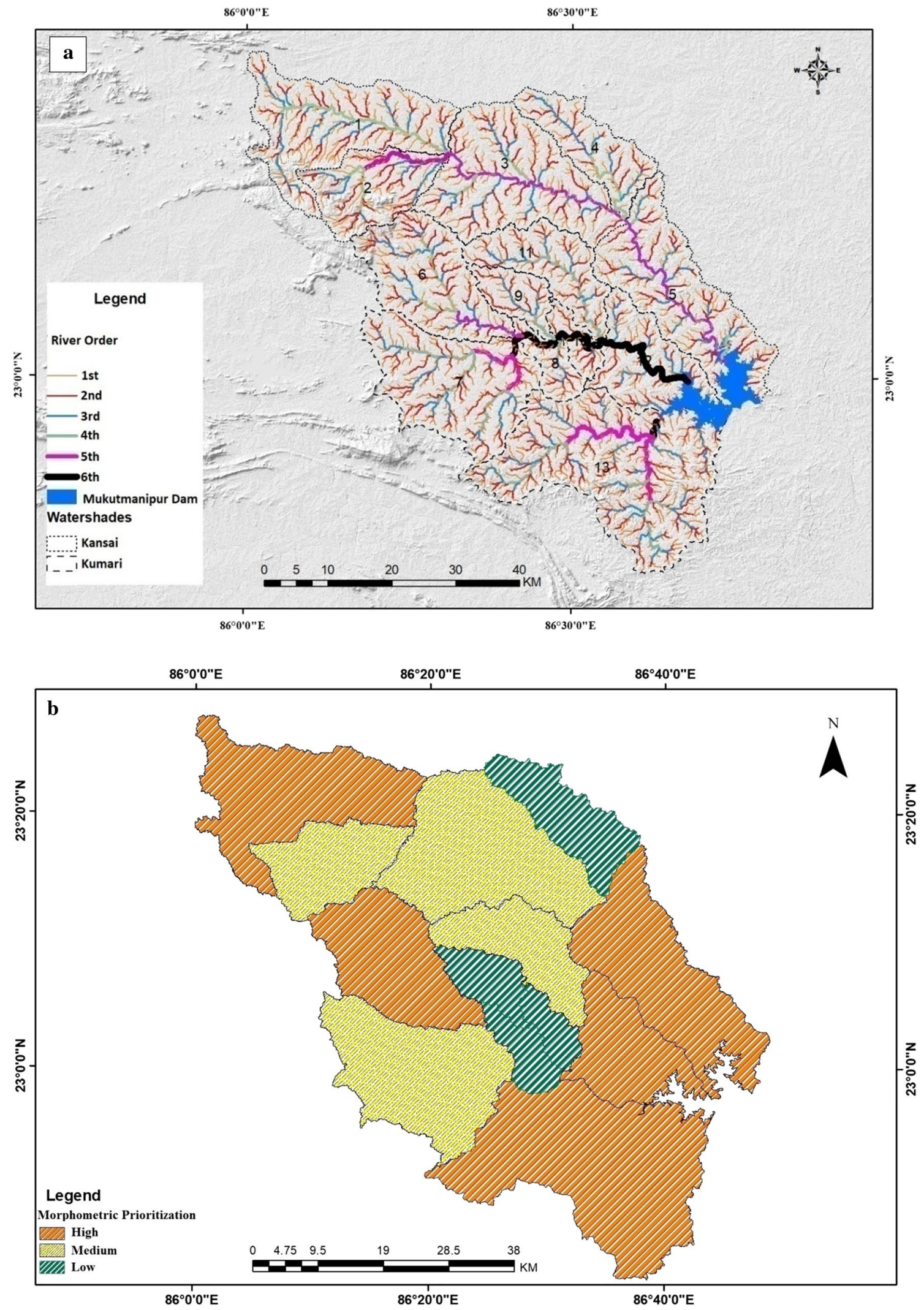

Fig. 3 a Drainage pattern and order and $\mathbf{b}$ priority based on morphometric parameters analysis in Kansai-Kumari reservoir catchment area 
Table 6 Geological-based assigned ranking and compound value in Kansai-Kumai interfluvial site

\begin{tabular}{|c|c|c|c|c|c|c|c|c|c|c|c|c|c|}
\hline SB & 1 & 2 & 3 & 4 & 5 & 6 & 7 & 8 & 9 & 10 & 11 & 12 & 13 \\
\hline $\mathrm{Al}$ & 3.1 & 13 & 1.8 & 10 & - & 6 & - & - & 12.2 & - & 20 & - & - \\
\hline $\mathrm{R}$ & 2 & 6 & 1 & 4 & & 3 & & & 5 & & 7 & - & - \\
\hline $\mathrm{Ch}$ & - & & - & - & - & - & - & - & - & - & - & 0.23 & 0.34 \\
\hline $\mathrm{R}$ & & & & & & & & & & & & 2 & 1 \\
\hline Dv & - & - & - & - & - & - & 1.6 & - & - & - & - & - & 4.45 \\
\hline $\mathrm{R}$ & & & & & & & 2 & & & & & & 1 \\
\hline $\mathrm{Ep}, \mathrm{H}$ & - & - & - & - & - & - & - & - & - & - & - & - & 0.56 \\
\hline $\mathrm{R}$ & & & & & & & & & & & & & 1 \\
\hline Gsbs & 23 & 12 & 7 & - & - & 3 & - & - & - & - & - & - & - \\
\hline $\mathrm{R}$ & 1 & 2 & 3 & & & 4 & & & & & & & \\
\hline $\mathrm{Gg}$ & 74 & 75 & 91 & 87 & 53 & 89 & 4.09 & 38 & 85 & 80 & - & 64 & 0 \\
\hline $\mathrm{R}$ & 7 & 6 & 1 & 3 & 9 & 2 & 11 & 10 & 4 & 5 & & 8 & 12 \\
\hline $\mathrm{Hs}$ & - & - & - & - & 0.8 & - & - & - & - & - & - & - & 10.5 \\
\hline $\mathrm{R}$ & & & & & 2 & & & & & & & & 1 \\
\hline Mfrs & - & - & - & - & 28 & 3 & 77 & 54 & - & 9.7 & 9.7 & 0.04 & 74.3 \\
\hline $\mathrm{R}$ & & & & & 4 & 7 & 1 & 3 & & 5 & 6 & 8 & 2 \\
\hline Os,S,C & - & - & - & - & - & - & - & - & - & - & - & - & 0.13 \\
\hline $\mathrm{R}$ & & & & & & & & & & & & & 1 \\
\hline Qbgg & - & - & - & 2 & - & - & - & - & - & - & - & - & \\
\hline $\mathrm{R}$ & & & & 1 & & & & & & & & & \\
\hline Rtb & - & - & 0.1 & 0 & 18 & - & 17.3 & 8 & 2.8 & 11 & 11 & 9.74 & 9.71 \\
\hline $\mathrm{R}$ & & & 9 & 10 & 1 & & 2 & 7 & 8 & 3 & 4 & 5 & 6 \\
\hline $\mathrm{CP}$ & 0.8 & 1 & 1.3 & 1 & 1.6 & 1 & 1.6 & 2 & 1.2 & 1.3 & 1 & 2.3 & 2.5 \\
\hline Priority & 1 & 1 & 2 & 2 & 2 & 2 & 3 & 3 & 1 & 2 & 1 & 3 & 3 \\
\hline
\end{tabular}

$\mathrm{Al}$, alluvium; Ch, Chotanagpur granite gneiss; Dv, Dolma volcanic; Ep,H, epidiorite, hornblende schist; Gsbs, garnetiferous sillimanite; Gg, granite gneiss; Hs, hornblende schist; Mfrs, Mahadeva formation red; Os,S,C, oxidised sand, silt, clay; Qbgg, quartz biotite granite gneiss; Rtb, Rajmahal Trap Basalt
The ranking assignment is important to determine erosion susceptibility in every lithological layer with the following erodibility index (Jasrotia et al. 2002; Patwary et al. 2009; Patel et al. 2012). Highest rank has been given from the lower aerial extent of alluvium structure due to its low erodibility while highest rank has been taken from the larger areal extent of the rest of geological structure due to its high erodibility. Sub-basin-wise lithological prioritization was obtained from $\mathrm{Cp}$ values in each sub-basin following the erodibility weight as per Jasrotia et al. (2002), Patwary et al. (2009) in supplementary result under 'Geological prioritization' section. SB1, 2, 9, 11 have given high priority rank (1) with the $C p$ value of $0.8-1$, medium priority rank (2) has been assigned to SB3, 4, 5, 6, 10 with the Cp value of 1-1.3, and low priority rank (3) was situated in SB7, 8, 12, 13 with the highest $\mathrm{Cp}$ value of 1.6-2.5 (Fig. 4b).

\section{Geomorphic set-up and its prioritization}

The geomorphic landscape is an indicator of erosion susceptibility in a basin with the following intensity of the erosion and deposition process. In terms of geomorphic landforms in the study area, it has been classified into eight classes such as buried pediment with lateritic capping $\left(872.84 \mathrm{~km}^{2}\right)$; flood plain deposits $\left(711 \mathrm{~km}^{2}\right)$; highly gullied land $\left(171 \mathrm{~km}^{2}\right)$; inter-hilly valley $\left(89 \mathrm{~km}^{2}\right)$; pediplain $\left(922 \mathrm{~km}^{2}\right)$; residual hills $\left(229 \mathrm{~km}^{2}\right)$; rocky outcrop $\left(294 \mathrm{~km}^{2}\right)$; and valley fill deposits $\left(214 \mathrm{~km}^{2}\right)$ as shown in Table 6 . Buried pediment with lateritic capping is the dominant (24\%), whereas least amount of landscape is inter-hilly valley (4\%) as shown in Table 7 (Fig. 5a). Erosion susceptibility in geomorphic landscape is determined by assigning rank through the following of run-off, landslide and denudation potentiality in each landform (Jasrotia et al. 2002; Patwary et al. 2009; Gioia et al. 2011). Buried pediment with lateritic capping, highly gullied land, inter-hill valley, pediplain, residual hills and rocky outcrop have high erosion susceptibility, while flood plain and valley fill deposits have low erosion susceptibility following Jasrotia et al. (2002), Patwary et al. (2009), Gioia et al. (2011) in supplementary result under 'Geomorphic prioritization' section. According to Cp value, SB2, 4, 7, 11, 13 fall under high priority class (1) with the $\mathrm{Cp}$ value ranging from 0.38 to $2, \mathrm{SB} 1,8,9,12$ fall under medium priority class (2) with the Cp value ranging from 2.375 to 3.37 , and 

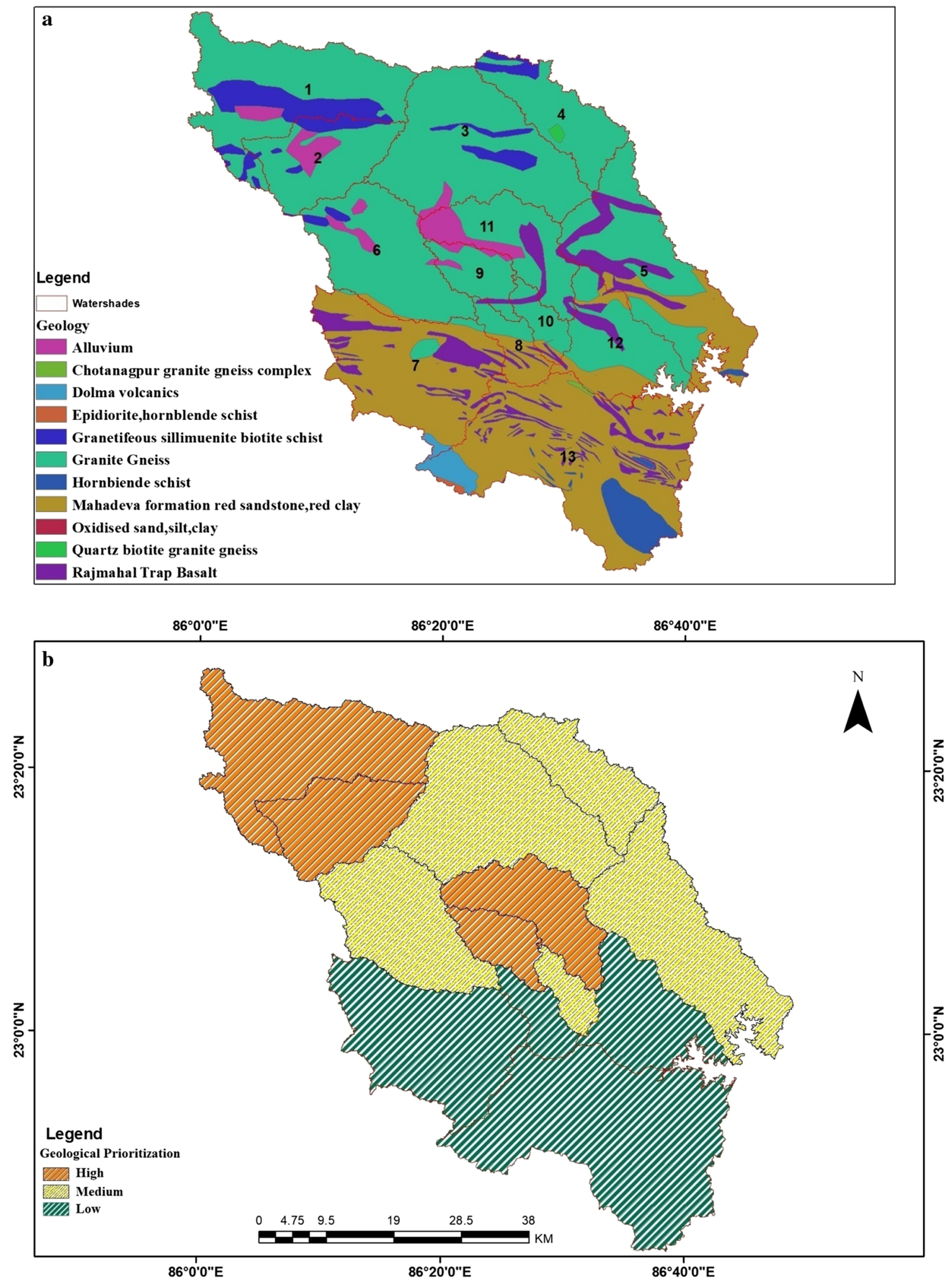

Fig. 4 a Geological set up in Kansai-Kumari reservoir catchment area and b priority based on geology in Kansai-Kumari reservoir catchment area 
Table 7 Geomorphic analysisbased assigned ranking and compound value in KansaiKumari inter-fluvial site

\begin{tabular}{|c|c|c|c|c|c|c|c|c|c|c|c|c|c|}
\hline SB & 1 & 2 & 3 & 4 & 5 & 6 & 7 & 8 & 9 & 10 & 11 & 12 & 13 \\
\hline Bplc & & & & & 3.26 & 27.7 & 94 & 64.1 & & 37.4 & & 23.3 & 47.1 \\
\hline $\mathrm{R}$ & & & & & 7 & 5 & 1 & 2 & & 4 & & 6 & 3 \\
\hline Fpd & 16.1 & 7.3 & 30.5 & 22.9 & 52 & 31.0 & 5.2 & 30.2 & 32 & 43.4 & 19.2 & 18.3 & 0.13 \\
\hline $\mathrm{R}$ & 4 & 3 & 9 & 7 & 13 & 10 & 2 & 8 & 11 & 12 & 6 & 5 & 1 \\
\hline $\mathrm{Hgl}$ & 0.01 & 1.7 & 38.6 & 0.70 & & & & & & & & & \\
\hline $\mathrm{R}$ & 4 & 2 & 1 & 3 & & & & & & & & & \\
\hline Ihv & 15 & 15 & & & & & & & & & & & \\
\hline $\mathrm{R}$ & 1 & 2 & & & & & & & & & & & \\
\hline $\mathrm{P}$ & 43.2 & 28 & 24.4 & 74.2 & 34 & 15.6 & & 0.001 & 63 & 7.08 & 74.8 & 38.5 & \\
\hline $\mathrm{R}$ & 4 & 7 & 8 & 2 & 6 & 9 & & 11 & 3 & 10 & 1 & 5 & \\
\hline $\mathrm{Rh}$ & 21.1 & 45. & 0.002 & & & 18.8 & & & & & & & \\
\hline $\mathrm{R}$ & 2 & 1 & 4 & & & 3 & & & & & & & \\
\hline Ro & & & & & & & & & & & & 12.3 & 42.3 \\
\hline $\mathrm{R}$ & & & & & & & & & & & & 2 & 1 \\
\hline Vfd & 4.41 & 1.11 & 6.37 & 2.061 & 9.68 & 6.661 & & 5.539 & 3.94 & 12.09 & 5.844 & 7.523 & 10.33 \\
\hline $\mathrm{R}$ & 4 & 1 & 7 & 2 & 10 & 8 & & 5 & 3 & 12 & 6 & 9 & 11 \\
\hline $\mathrm{Cp}$ & 2.375 & 2 & 3.625 & 1.75 & 4.5 & 4.375 & 0.38 & 3.25 & 2.13 & 4.75 & 1.625 & 3.375 & 2 \\
\hline Priority & 2 & 1 & 3 & 1 & 3 & 3 & 1 & 2 & 2 & 3 & 1 & 2 & 1 \\
\hline
\end{tabular}

Bplc, buried pediments with lateritic capping; Fpd, flood plain deposits; Hgl, highly gullied land; Ihv, interhill valley; P, pediplain; Rh, residual hills; Ro, rocky outcrop; Vfd, valley fill deposits lower priority class (3) has been given in rest sub-basin out of 13 sub-basins with the highest $\mathrm{Cp}$ value varying from 3.75 to 4.75 (Fig. 5b).

\section{Land use and land cover analysis (LULC) and its prioritization}

Drainage pattern and its coverage area are strongly influenced by LULC patterns and also significantly impact on soil erosion susceptibility through the controlling of moisture content, infiltration, evapo-transpiration as well as interception process in a basin (Rashid and Romshoo 2013; Romshoo et al. 2012). Vegetation cover and root biomass play a vital role in controlling the rate of erosion (Carlos et al. 2012; Badar et al. 2013). On the other hand, LULC has another important inimitable factor for the determination of watershed prioritization and management (Javed et al. 2009, 2011). LULC in this study area has been categorised into seven types such as crop $\left(1648 \mathrm{~km}^{2}\right)$; dense forest $\left(221 \mathrm{~km}^{2}\right)$; laterite $\left(632 \mathrm{~km}^{2}\right)$; open forest $\left(368 \mathrm{~km}^{2}\right)$; river $\left(256 \mathrm{~km}^{2}\right)$; settlement $\left(267 \mathrm{~km}^{2}\right)$; and water body $\left(121 \mathrm{~km}^{2}\right)$. Cropland is the dominant LULC category including single- and double-crop cover with $46.86 \%$, while water body covers very least area with $3.46 \%$ as shown in Table 8 (Fig. 6a). Rank assigned has been given on the basis of erosion susceptibility in each LULC categories (Chauhan et al. 2016). Highest rank has been assigned for the area of larger extent with less vegetation, cropland, laterite, water body, settlement and river, whereas lowest rank has been assigned for the higher areal extent of dense and open forest following Jasrotia et al. (2002), Altaf et al. (2014), Mahala (2018) in supplementary result under 'Land use land cover prioritization' section. Priority class reveals that SB3, 4, 9, 10, 11 reached the high priority class (1) with the Cp value of 3.33-5.17; SB1, 5, 6, 7 fall under the middle priority class (2) with the Cp value of 5.33-5.67; and low priority class (3) has been assigned to SB2, 8, 12, 13 with the Cp value of 5.83-8.77 (Fig. 6b).

\section{Slope characteristic and its prioritization}

This is one of the important specific features of surface expression which is positively influenced by erosion susceptibility in a watershed (Chauhan et al. 2016; Meshram and Sharma 2017). High erosion susceptibility class is situated in a high percentage of slope or very steep slope in order of particle detachment and low erosion susceptibility class associated with low percentage of slope or gentle slope in order to restrict soil erosion (Jasrotia et al. 2002; Patwary et al. 2009; Farhan and Anaba 2016). Final priority rank has been given as the following descending manner of the $\mathrm{Cp}$ value in every sub-basin following Jasrotia et al. (2002), Patwary et al. (2009), Farhan and Anaba (2016) in supplementary result under 'Slope prioritization' section. Most of the basin area falls under lower percentage class or gentle slope $\left(<5^{\circ}\right)$ which varies from 59 to $78 \%$, whereas minimum basin area falls under highest percentage class or very steep slope $\left(>15^{\circ}\right)$ which varies from 0.06 to $8 \%$ in the study area shown in Table 8 (Fig. 7a). SB1, 3, 4, 7, 9 

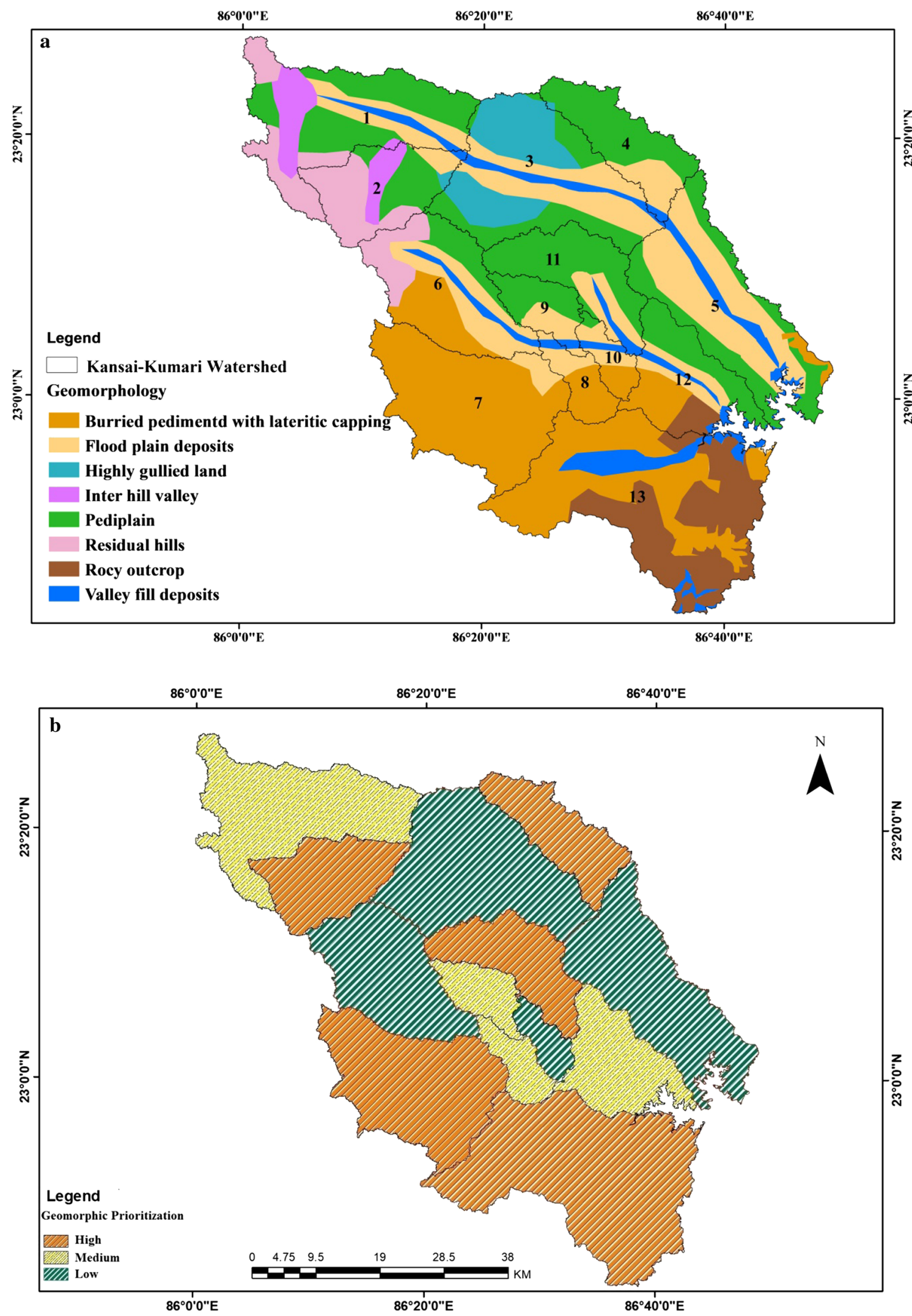

Fig. 5 a Geomorphic set up in Kansai-Kumari reservoir catchment area and b priority based on geomorphic parameters analysis in KansaiKumari reservoir catchment area 
Table 8 LULC-based assigned ranking and compound value in Kansai-Kumari inter-fluvial site

\begin{tabular}{llllllllllllll}
\hline SB & 1 & 2 & 3 & 4 & 5 & 6 & 7 & 8 & 9 & 10 & 11 & 12 & 13 \\
\hline Cr & 61.96 & 32.88 & 61.35 & 59.27 & 35.94 & 57.12 & 41.64 & 41.82 & 68.31 & 56.21 & 60.2 & 39.74 & 28.93 \\
AR & 2 & 10 & 2 & 4 & 9 & 5 & 7 & 7 & 1 & 6 & 3 & 8 & 11 \\
Df & 6.9874 & 21.181 & 0.8583 & 0.2081 & 4.0116 & 3.9837 & 3.036 & 6.1638 & 0.0074 & 0.285 & 0.2826 & 2.732 & 15.394 \\
AR & 10 & 12 & 4 & 2 & 8 & 7 & 6 & 9 & 1 & 3 & 3 & 5 & 11 \\
L & 12.65 & 27.918 & 11.186 & 11.524 & 22.647 & 11.403 & 28.89 & 21.61 & 7.3789 & 10.73 & 16.525 & 20.898 & 19.211 \\
AR & 8 & 2 & 9 & 9 & 3 & 9 & 1 & 4 & 11 & 10 & 7 & 5 & 6 \\
Of & 3.6579 & 8.0409 & 5.0996 & 4.3104 & 11.412 & 6.8716 & 10.66 & 15.896 & 7.5052 & 8.593 & 7.484 & 14.192 & 21.505 \\
AR & 1 & 7 & 3 & 2 & 10 & 4 & 9 & 12 & 6 & 8 & 5 & 11 \\
Wb & 9.9941 & 7.1752 & 13.208 & 15.573 & 15.001 & 12.976 & 8.998 & 7.7147 & 11.33 & 14.31 & 9.3577 & 13.538 & 6.3258 \\
AR & 6 & 7 & 3 & 1 & 1 & 4 & 6 & 7 & 5 & 2 & 6 & 3 \\
St & 4.75 & 2.8 & 8.294 & 9.115 & 10.99 & 7.645 & 6.773 & 6.798 & 5.474 & 9.868 & 6.149 & 8.9 & 8.639 \\
AR & 7 & 8 & 3 & 2 & 1 & 4 & 5 & 5 & 6 & 2 & 5 & 3 \\
CP & 5.67 & 7.67 & 4 & 3.33 & 5.33 & 5.5 & 5.67 & 7.33 & 5 & 5.17 & 4.83 & 5.83 & 8.67 \\
Priority & 2 & 3 & 1 & 1 & 2 & 2 & 2 & 3 & 1 & 1 & 1 & 3 \\
\hline
\end{tabular}

$\mathrm{Cr}$, crop; Df, dense forest; L, laterite; Of, open forest; $\mathrm{Wb}$, water body; St, settlement

achieved high priority class (1) denoted by highest $\mathrm{Cp}$ value of 14.45-17.57, whereas low priority class (3) was situated in SB2, 5, 12, 13 with the lower Cp value ranging from 12.19 to 12.95 . Rest of the sub-basin have fallen under the medium priority class (2) due to the presence of medium Cp value (Fig. 7b). The result shows that high erosion susceptibility is due to the presence of high priority class while low erosion susceptibility is due to the presence of low priority class in the entire catchment area.

\section{Soil characteristic and its prioritization}

Soil erosion and landslide activities are greatly influenced by physical and chemical properties of soil (Srivastava et al. 2005). Code-wise soil classification in the study area depends on several types of soil properties like colour, moisture content, texture and depth to assign on its erosion susceptibility of every soil class (Chauhan et al. 2016). Soil code in the study area has been classified into eight types, i.e. Fine $\left(559 \mathrm{~km}^{2}\right)$; Fine Loamy $\left(688 \mathrm{~km}^{2}\right)$; Fine Loamy-Coarse Loamy (159 $\left.\mathrm{km}^{2}\right)$; Fine Loamy, Type Haplustalfs $\left(738 \mathrm{~km}^{2}\right)$; Gravelly Loam $\left(222 \mathrm{~km}^{2}\right)$; Gravelly Loam Loam (1050 km²); Loamy, Lethic Haplustaifs $\left(91 \mathrm{~km}^{2}\right)$; and Loamy Skeletal, Lethic Ustorthents $\left(10.62 \mathrm{~km}^{2}\right)$. Gravelly Loam Loam (29\%) and Loamy Skeletal, Lethic Ustorthents $(0.30 \%)$ cover maximum and minimum area extent, respectively (Table 9 and Fig. 8a). On the contrary, soil erodibility factor $(\mathrm{K})$ plays a vital role in determining the basin prioritization following on assigning a ranking of erosion susceptibility (Sahaar 2013; Chauhan et al. 2016; Ganasri and Ramesh 2016). Fine Loamy-Coarse Loamy; Gravelly Loam; Gravelly loam-Loam; Loamy-Skeletal, Lethic Ustorthents; Loamy,
Lethic Haplustaifs have been taken as high erosion susceptibility for low K value, while Fine, Fine Loamy and Fine loamy, Type Haplustafs have been taken as low erosion susceptibility for high $\mathrm{K}$ value explaining in supplementary result under 'Soil prioritization' section. Priority result shows that $\mathrm{SB} 3,9,10,12$ reached highest priority class (1) with the $\mathrm{Cp}$ value of $0.125-1.75$ and medium priority class (2) has been assigned to SB2, 4, 8, 11 with the $\mathrm{Cp}$ value of 2-2.625. SB1, 5, 6, 7, 13 have been given low priority class (3) due to the presence of the highest $\mathrm{Cp}$ value (2.75-4.13) (Fig. 8b).

\section{Sub-basin-wise final priority of all themes}

Sub-basin-wise prioritization has been prepared from the final compound value of seven selected theme, i.e. morphometric, geological, morphological set-up, LULC, slope and soil, to assess the role of erosion susceptibility (Table 10). Finally, basin prioritization is divided into three categories, i.e. high, medium and low, on the basis of compile Cp value. Result shows that SB2, 11, 12, 13 achieved high priority rank due to the presence of low $\mathrm{Cp}$ value (3-3.5); SB4, 7, 8, 9, 10 achieved low priority rank with the high $\mathrm{Cp}$ value (4-4.5) and SB1, 3, 5, 6 reached medium priority rank due to the presence of medium $\mathrm{Cp}$ value (3.5-4) in study area (Table 11, Fig. 9). On the other hand, all integrated priority rank helps in determining more or less erosion-prone site to take appropriate erosion control strategies with the analysis of erosion risk assessment used by hypsometric analysis and denudation rate measurement. 

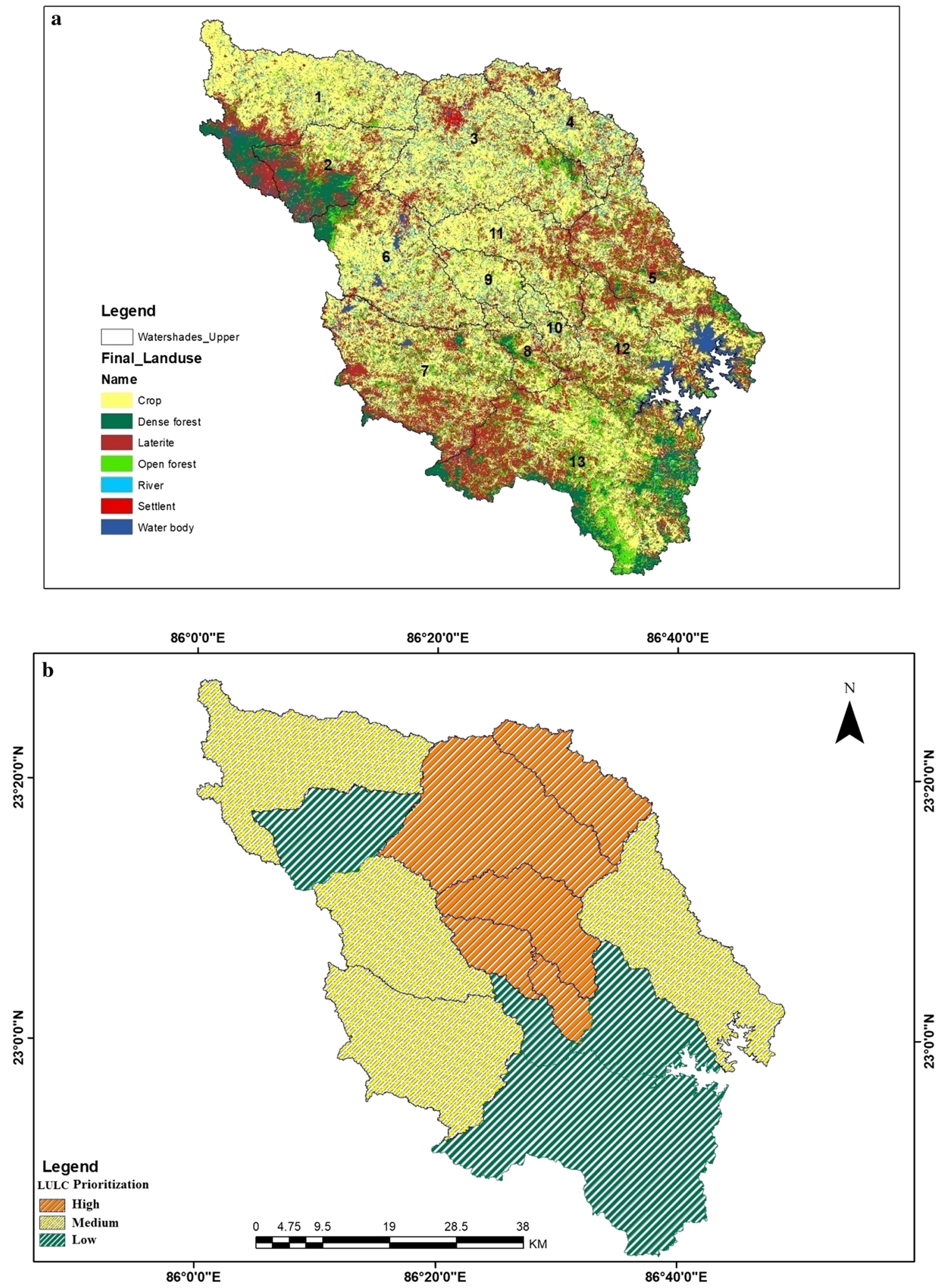

Fig. 6 a LULC in Kansai-Kumari reservoir catchment area and b priority based on LULC parameters analysis in Kansai-Kumari reservoir catchment area 

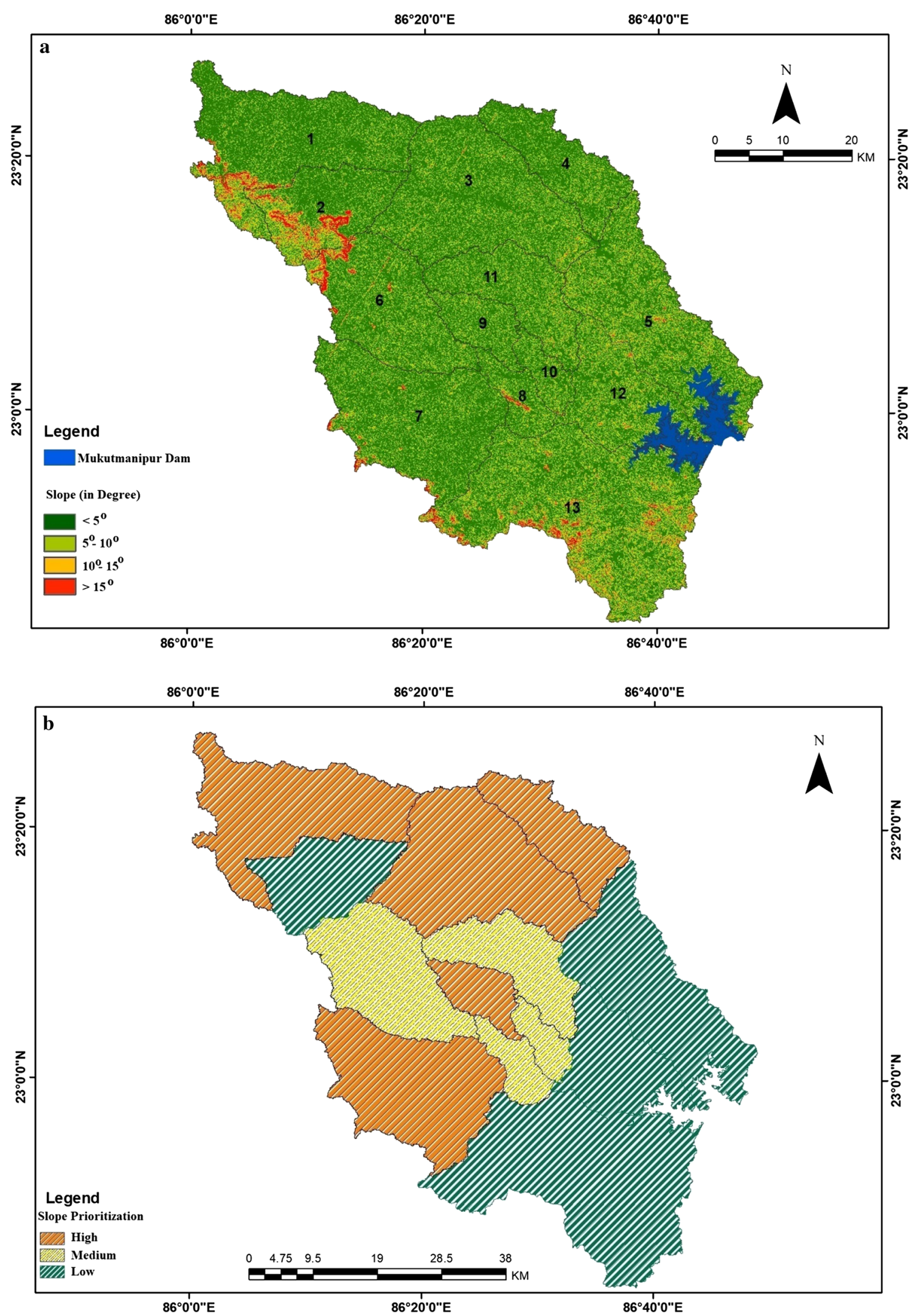

Fig. 7 a Slope analysis in Kansai-Kumari reservoir catchment area and b priority based on slope parameter in Kansai-Kumari reservoir catchment area 
Table 9 Slope-based assigned ranking and compound value in Kansai-Kumari inter-fluvial site

\begin{tabular}{llrlrlrllll}
\hline $\mathrm{SB}$ & $<5^{\circ}$ & $\mathrm{R}$ & $5^{\circ}-10^{\circ}$ & $\mathrm{R}$ & $10^{\circ}-15^{\circ}$ & $\mathrm{R}$ & $>15^{\circ}$ & $\mathrm{R}$ & $\mathrm{Cp}$ & Priority \\
\hline 1 & 75.18244 & 10 & 19.28495 & 13 & 3.305605 & 6 & 2.227005 & 4 & 8.25 & 1 \\
2 & 59.19048 & 1 & 24.50671 & 8 & 8.313692 & 1 & 7.989121 & 1 & 2.75 & 3 \\
3 & 75.29181 & 11 & 22.72247 & 10 & 1.840636 & 12 & 0.14509 & 10 & 10.75 & 1 \\
4 & 78.69025 & 13 & 19.93992 & 12 & 1.306478 & 13 & 0.063355 & 11 & 12.25 & 1 \\
5 & 66.97478 & 4 & 28.36114 & 3 & 4.189066 & 3 & 0.475013 & 7 & 4.25 & 3 \\
6 & 69.30083 & 5 & 24.21646 & 9 & 3.558066 & 5 & 2.924636 & 2 & 5.25 & 2 \\
7 & 76.22189 & 12 & 20.89367 & 11 & 1.965446 & 10 & 0.918988 & 6 & 9.75 & 1 \\
8 & 70.92389 & 7 & 24.59651 & 7 & 2.892367 & 8 & 1.587226 & 5 & 6.75 & 2 \\
9 & 73.25019 & 9 & 24.78512 & 6 & 1.906961 & 11 & 0.057735 & 11 & 9.25 & 1 \\
10 & 70.78948 & 6 & 25.93716 & 4 & 2.975594 & 7 & 0.297761 & 9 & 6.5 & 2 \\
11 & 71.42723 & 8 & 25.77875 & 5 & 2.642332 & 9 & 0.151692 & 10 & 8 & 2 \\
12 & 66.82887 & 3 & 28.65748 & 2 & 4.0447 & 4 & 0.46895 & 8 & 4.25 & 3 \\
13 & 59.23098 & 2 & 30.76259 & 1 & 7.30174 & 2 & 2.704688 & 3 & 2 & 3 \\
\hline
\end{tabular}

\section{Risk assessment of erosion susceptibility}

\section{Hypsometric assessment}

The hypsometric characteristic especially hypsometric curve in this study area is determined by landmass area from ten class distributions of elevation under the specific contour break points above the drainage outlet following Kaliraj method (2014). Sub-basin-wise landmass distribution shows that most of the area falls under $100-300 \mathrm{~m}\left(114 \mathrm{~km}^{2}\right.$ of $213-345 \mathrm{~m}$ in SB1; $35 \mathrm{~km}^{2}$ of $229-362 \mathrm{~m}$ in SB2; $71 \mathrm{~km}^{2}$ of $178-260 \mathrm{~m}$ in SB3; $35.41 \mathrm{~km}^{2}$ of $172-242 \mathrm{~m}$ in SB4; $72 \mathrm{~km}^{2}$ of $112-207$ in SB5; $89 \mathrm{~km}^{2}$ of 154-304 $\mathrm{m}$ in SB6; $123 \mathrm{~km}^{2}$ of $168-292 \mathrm{~m}$ in SB7; $13.46 \mathrm{~km}^{2}$ of $169-253 \mathrm{~m}$ in SB8; $14 \mathrm{~km}^{2}$ of $184-246 \mathrm{~m}$ in SB9; $11.37 \mathrm{~km}^{2}$ of $153-190 \mathrm{~m}$ in SB10; $26.43 \mathrm{~km}^{2}$ of $153-268 \mathrm{~m}$ in SB11; $32 \mathrm{~km}^{2}$ of $117-212 \mathrm{~m}$ in SB12 and $150 \mathrm{~km}^{2}$ of $123-282 \mathrm{~m}$ in SB13). On the contrary, average small area was concentrated above $350 \mathrm{~m}$ in this study area $\left(9.45 \mathrm{~km}^{2}\right.$ of $345-609 \mathrm{~m}$ in SB1; $11 \mathrm{~km}^{2}$ of $406-628 \mathrm{~m}$ in SB2; $13 \mathrm{~km}^{2}$ of $260-309 \mathrm{~m}$ in SB3; $5.41 \mathrm{~km}^{2}$ of $145-186$ and $256-284 \mathrm{~m}$ in SB4; $9.81 \mathrm{~km}^{2}$ of $207-265 \mathrm{~m}$ in SB5; $3.46 \mathrm{~km}^{2}$ of $304-655 \mathrm{~m}$ in SB6; $2.77 \mathrm{~km}^{2}$ of $292-584 \mathrm{~m}$ in SB7; $0.84 \mathrm{~km}^{2}$ of $253-320 \mathrm{~m}$ in SB8; $2.68 \mathrm{~km}^{2}$ of $246-283 \mathrm{~m}$ in SB9; $1.89 \mathrm{~km}^{2}$ of $203-253 \mathrm{~m}$ in $10 ; 3.21 \mathrm{~km}^{2}$ of $268-301 \mathrm{~m}$ in $\mathrm{SB} 11 ; 2.61 \mathrm{~km}^{2}$ of $212-260 \mathrm{~m}$ in SB12 and $4.87 \mathrm{~km}^{2}$ of $282-481 \mathrm{~m}$ in SB13) as shown in Fig. 10. It is a point that maximum landmass was concentrated on lower elevation site while minimum landmass area was concentrated on higher elevation site of identified contour break points in every sub-basin.

The hypsometric curve is divided into three types, i.e. convex up, convex and concave curve, whereas HI is divided into three types, i.e. high, medium and low. Convexup curves are situated in high $\mathrm{HI}$ value $(\mathrm{HI}>0.60)$ denoting youth or equilibrium stage, convex curve is situated in medium HI value (HI 0.60-0.35) denoting mature or equilibrium stage, and concave curves are situated in low HI value $(\mathrm{HI}<0.35)$ denoting old or monadnock stage (Strahler 1952; Rosenblatt et al. 1994). HI value in this study area reveals that $\mathrm{SB} 1,2,3,4,5,8,9,10,11$ and 12 fall under late youth or inequilibrium stage for $\mathrm{HI}$ value ranging from 0.4 to 0.542 ; SB6, 7 reached old or monadnock stage for $\mathrm{HI}$ value of 0.29 ; and SB13 achieved equilibrium stage for $\mathrm{HI}$ value of 0.35 (Table 12 and Fig. 11). Therefore, most of the hypsometric curves in this study area have the convex-up type with medium HI value which reveals that landforms are an undissected or inequilibrium stage. Average landmass distribution shows that high $\mathrm{HI}$ value is always present in maximum landmass distribution under high elevated contour break points due to the presence of high priority rank of all selected themes and vice versa.

\section{Denudation rate assessment}

This is another indirect estimation way of erosion risk assessment based on hierarchical drainage network of morphometric and geomorphic activities. The prime objective of this estimation is to assess the quantity of suspended sediment transport and role of tectonic activity through the analysis of slope variation in a basin (Gioia et al. 2011; Kaliraj et al. 2015). Drainage density (D), hierarchical anomaly number (Ga), hierarchical anomaly density (ga) and hierarchical anomaly index $(\Delta a)$ are used for the estimation of denudation rate $(\mathrm{Tu})$ in this study area. $\mathrm{D}$ in this catchment area ranges from 0.99 (SB4) to $1.16 \mathrm{~km} / \mathrm{km}^{2}$ (SB13) with the average value of $1.07 \mathrm{~km} / \mathrm{km}^{2}$ in this study, whereas $\mathrm{Ga}$ varies from 711 (SB13) to 39 (SB10) within the average value of 229 (u I-VI). Result shows that stream order-wise steep slope or elevated surface or highly existing rock surface leads to increase the $D$ value in accordance with ascending manner of stream order along with Ga (Table 12 and Fig. 12), while lowest density was situated in gentle slope

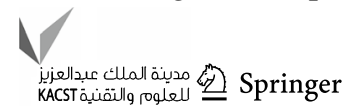



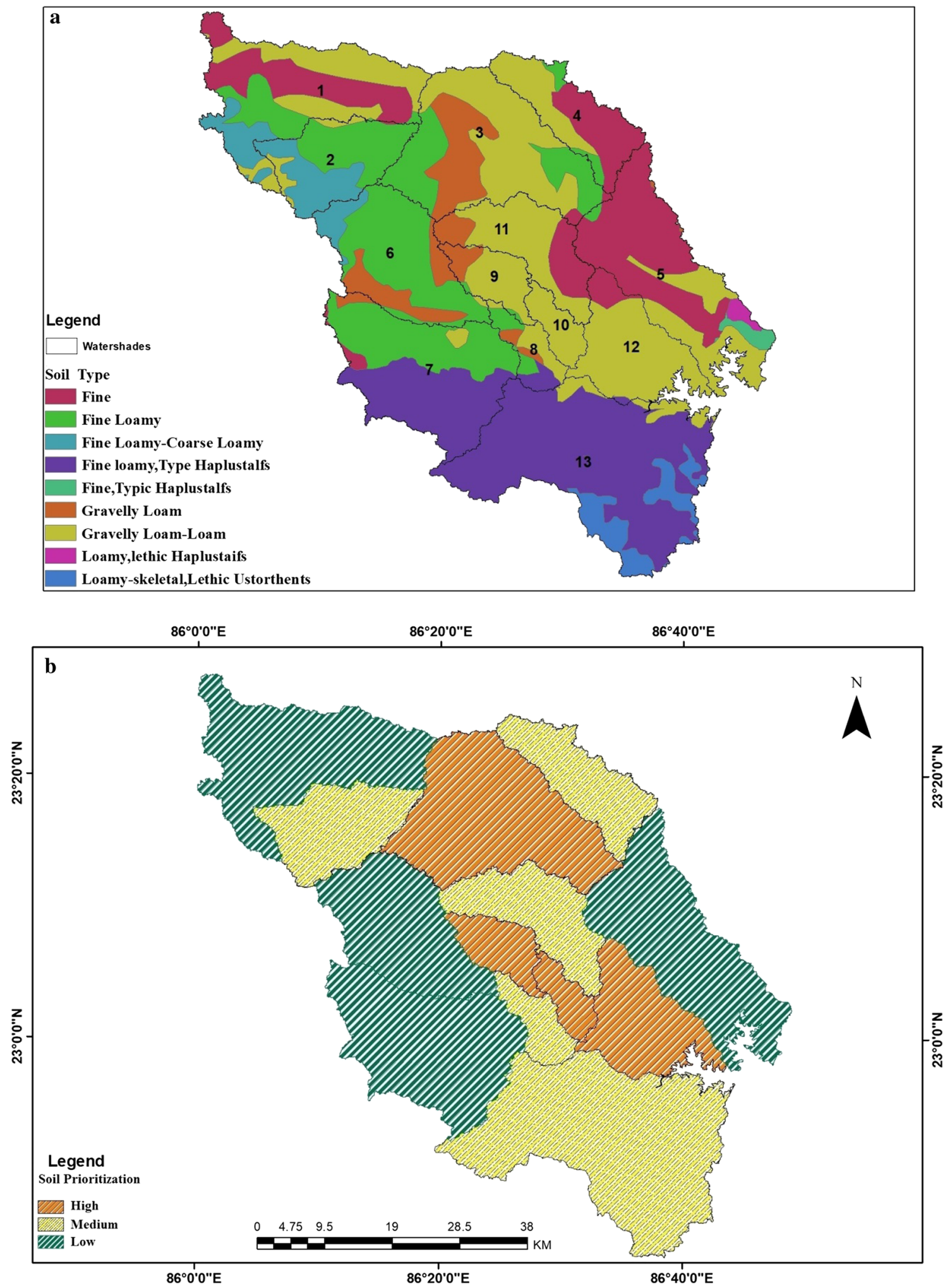

Fig. 8 a Soil type in Kansai-Kumari inter-fluvial site and b priority based on soil type analysis in Kansai-Kumari reservoir catchment area 
Table 10 Soil-based assigned ranking and compound value in Kansai-Kumari inter-fluvial site

\begin{tabular}{llllllllllllll}
\hline SB & 1 & 2 & 3 & 4 & 5 & 6 & 7 & 8 & 9 & 10 & 11 & 12 & 13 \\
\hline F & 35.7 & 0.38 & 1.36 & 49.57 & 62.61 & & 2.145 & 0.0008 & 4.17 & 24.03 & 10.75 & \\
R & 8 & 2 & 3 & 9 & 10 & & 4 & 1 & 5 & 7 & 6 & \\
Fl & 14.4 & 51.63 & 27.46 & 9.21 & 0.91 & 67.03 & 44.19 & 27.66 & 3.56 & & & \\
R & 4 & 8 & 5 & 3 & 1 & 9 & 7 & 6 & 2 & & & \\
Fl-Cl & 12.6 & 39.87 & & & & 9.93 & & & & & & & \\
R & 2 & 1 & & & & 3 & & & & & & & \\
Flth & & & & & 4.22 & & 50.08 & 21.09 & & & & 1.02 & 80.21 \\
R & & & & & 2 & & 4 & 3 & & & & 1 & 5 \\
Gl & & & 23.46 & & 0.22 & 22.44 & 1.78 & 12.98 & 20.91 & & 10.95 & & \\
R & & & 1 & & 7 & 2 & 6 & 4 & 3 & & 5 & & \\
Gll & 37.2 & 8.1 & 47.73 & 41.21 & 29.28 & 0.59 & 1.78 & 38.25 & 75.52 & 100 & 65.01 & 88.21 & 5.43 \\
R & 8 & 10 & 5 & 6 & 9 & 13 & 12 & 7 & 3 & 1 & 4 & 2 & 11 \\
Ls,Lu & & & & & & & & & & & & & 14.36 \\
R & & & & & & & & & & & & & 1 \\
L,Lh & & & & & 2.74 & & & & & & & & \\
R & & & & & 1 & & & & & & & & \\
cp & 2.75 & 2.625 & 1.75 & 2.25 & 3.75 & 3.375 & 4.125 & 2.625 & 1.625 & 0.125 & 2 & 1.125 & 2.125 \\
rank & 3 & 2 & 1 & 2 & 3 & 3 & 3 & 2 & 1 & 1 & 2 & 1 & 2 \\
\hline
\end{tabular}

F, Fine; Fl, Fine Loamy; Fl-Cl, Fine Loamy-Coarse Loamy; Flth, Fine loamy,Type Haplustafs; Gl, Gravelly Loam; Gll, Gravelly Loam-Loam; Ls,Lu, Loamy-Skeletal,Lethic Ustorthents; L,Lh, Loamy,Lethic Haplustaifs

Table 11 Sub-basin-wise final priority of six themes in the entire catchment area

\begin{tabular}{|c|c|c|c|c|c|c|c|c|c|}
\hline SB & Morphometric & Land use & Geology & geomorphology & Hypsometric & Slope & Soil & Final $\mathrm{cp}$ & Priority \\
\hline 1 & 3.363636 & 5.666667 & 0.8 & 2.375 & 0.36065 & 8.25 & 2.75 & 3.366565 & 1 \\
\hline 2 & 5.636364 & 7.666667 & 0.8 & 2 & 0.402023 & 2.75 & 2.625 & 3.125722 & 1 \\
\hline 3 & 5.818182 & 4 & 1.3 & 3.625 & 0.518382 & 10.75 & 1.75 & 3.965938 & 3 \\
\hline 4 & 7.090909 & 3.333333 & 1.4 & 1.75 & 0.541894 & 12.25 & 2.25 & 4.088019 & 3 \\
\hline 5 & 4 & 5.333333 & 1.6 & 4.5 & 0.494205 & 4.25 & 3.5 & 3.382505 & 1 \\
\hline 6 & 4.909091 & 5.5 & 1.3 & 4.375 & 0.286647 & 5.25 & 3.375 & 3.57082 & 2 \\
\hline 7 & 5.181818 & 5.666667 & 1.6 & 0.375 & 0.285141 & 9.75 & 3.625 & 3.783375 & 2 \\
\hline 8 & 7.090909 & 7.333333 & 2 & 3.25 & 0.400395 & 6.75 & 2.25 & 4.15352 & 3 \\
\hline 9 & 8.272727 & 5 & 1.2 & 2.125 & 0.498025 & 9.25 & 1.625 & 3.995822 & 3 \\
\hline 10 & 9.272727 & 5.166667 & 1.3 & 4.75 & 0.472288 & 6.5 & 0.125 & 3.940955 & 2 \\
\hline 11 & 6 & 4.833333 & 1 & 1.625 & 0.512306 & 8 & 2 & 3.424377 & 2 \\
\hline 12 & 5 & 5.833333 & 2.3 & 3.375 & 0.43194 & 4.25 & 1 & 3.170039 & 1 \\
\hline 13 & 2.454545 & 8.666667 & 2.5 & 2 & 0.338729 & 2 & 1.5 & 2.779992 & 1 \\
\hline
\end{tabular}

or plain surface or low existing rock surface as well as lowest number of $\mathrm{Ga}$. On the other hand, stream order-wise $\mathrm{Ga}$ generates perfectly tree-shaped structure in every sub-basin which reveals that basin slope plays a vital role in initiating drainage network.

Hierarchical anomaly density (ga) in this study area ranges from 1.29 (SB13) to 0.70 (SB2) within the average value of 0.81 , whereas hierarchical anomaly index $(\Delta a)$ ranges from 1.35 (SB8) to 1.23 (SB9) within the average value of 1.28. Sub-basin-wise $\Delta a$ value varies due to the presence of $\mathrm{u}-\mathrm{I}$ and ga. The result denotes that entire drainage network as hierarchical form is controlled by lithological structure mainly high-altitude steep slope region due to value of $\Delta a$ more than one (Ciccacci et al. 2003). Finally, Tu rate in the 13 sub-basin produces from 95.86 (SB13) to $79.43 \mathrm{t} / \mathrm{km}^{2} /$ year (SB9) within the average value of $84.94 \mathrm{t} /$ $\mathrm{km}^{2} /$ year. Slope, D, ga, $\Delta a$ and other associated morphogenetic factors and hierarchical drainage outlet play vital role in initiating the rate of Tu (Bonnet and Crave 2003; Whipple 2009; Bahrami 2013). On the other hand, denudation 


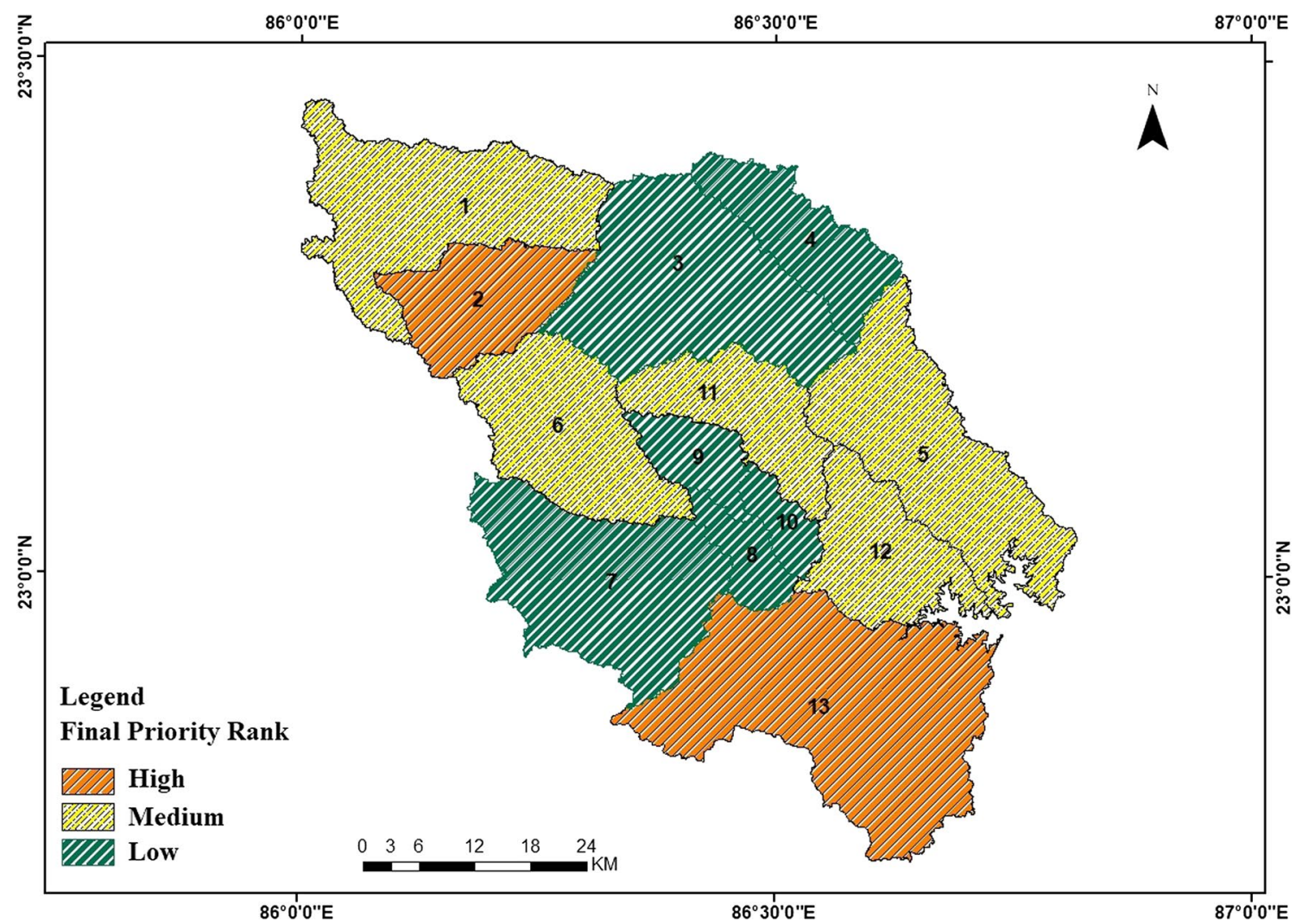

Fig. 9 Sub-basin-wise final composite prioritization in Kansai-Kumari reservoir catchment area

intensity produces suspended sediment yield through the generation of several morphometric landforms, which transported suspension manner per unit area of sub-basin.

\section{The relationship between basin prioritization and risk assessment status}

The present study address that basin prioritization has a positive relationship with soil erosion susceptibility $(r=0.5)$ through the integrated analysis of morphometric, geological, geomorphic set-up, LULC, slope and soil characteristics. But risk assessment status shows that morphometric aspects are controlled by geological and geomorphic set-up, whereas LULC depends on soil, slope and morphometric priority in a drainage basin. The result in this study denotes that SB13, 2 fall under high basin priority and high-risk assessment rank, whereas SB3, 4, 9 reached low basin priority and low risk rank, but both risk rank reached under the mature stage of geological setting (Tables 11, 12). SB6, 7 reached medium priority of basin status and medium risk rank, but geological setting falls under old stage due to the presence of erosionprone soil types of Fine Loamy and Fine Loamy, Haplustafs, while SB7, 8, 10 reached low priority rank, but denudation rate has medium rank due to the presence of erosion-prone LULC patterns like cropland and laterite cover (Figs. 9, 12).
It is a point that basin priority and erosion susceptibility do not depend on morphometric set-up but also depend on other associated parameters like geological, geomorphic, LULC, slope and soil characteristic.

\section{Conclusions and findings}

Basin prioritization is a holistic approach through the integration of determinant themes like morphometric, lithological, geomorphic set-up, LULC, slope and soil types in the study area under the GIS platform. The hierarchical drainage system, hydrological process, geomorphic landscape evolution and stream watershed relationship could be better understood by basin priority status. The present study provides the basin priority rank of individual determinant themes, the role of erosion susceptibility in every determinant theme as well as sub-basin-wise spatial distribution of suspended sediment transport per unit basin area. Erosion susceptibility is determined by the analysis of hypsometric characteristic and suspended sediment transport estimated by denudation rate. The result of this study reveals that SB13, 2 have high erosion risk rank or high denudation rate (tu $>90 \mathrm{t} / \mathrm{km}^{2} /$ year) due to the presence of low priority rank of morphometric, geomorphic, slope, soil and high priority rank of lithological 

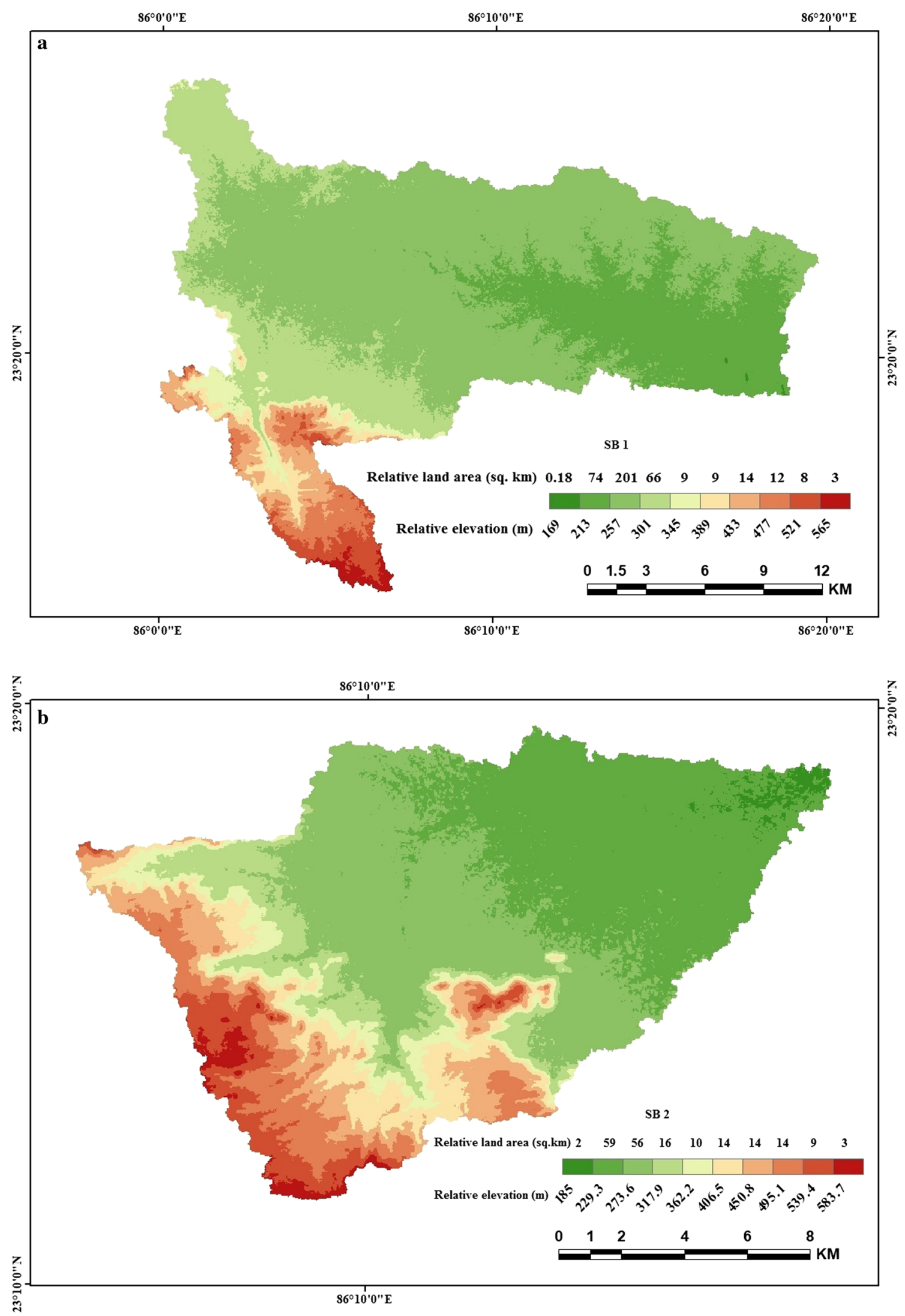

Fig. 10 a-m Sub-basin-wise hypsometric analysis of relative land area distribution based on ten class relative elevations 

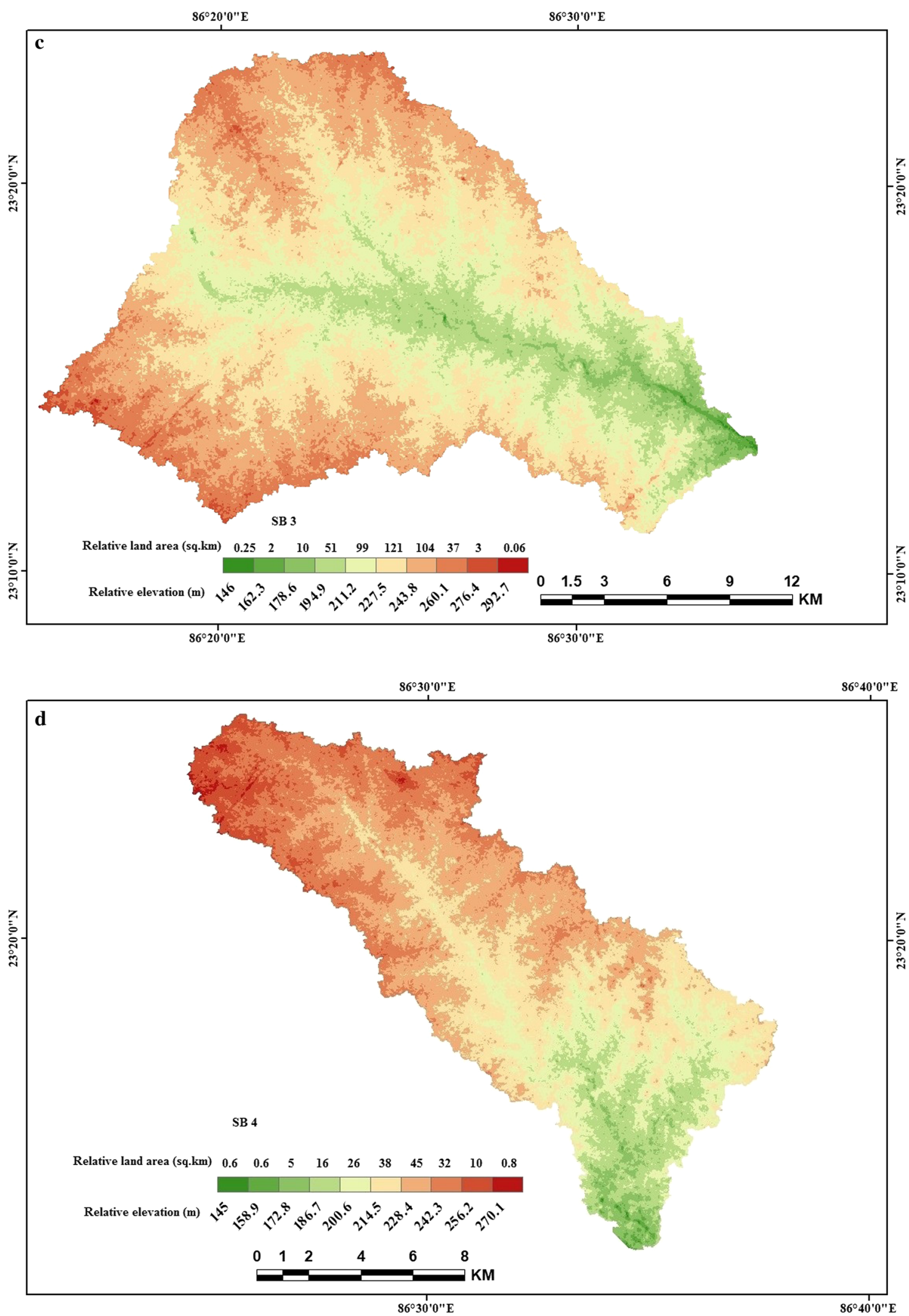

Fig. 10 (continued) 


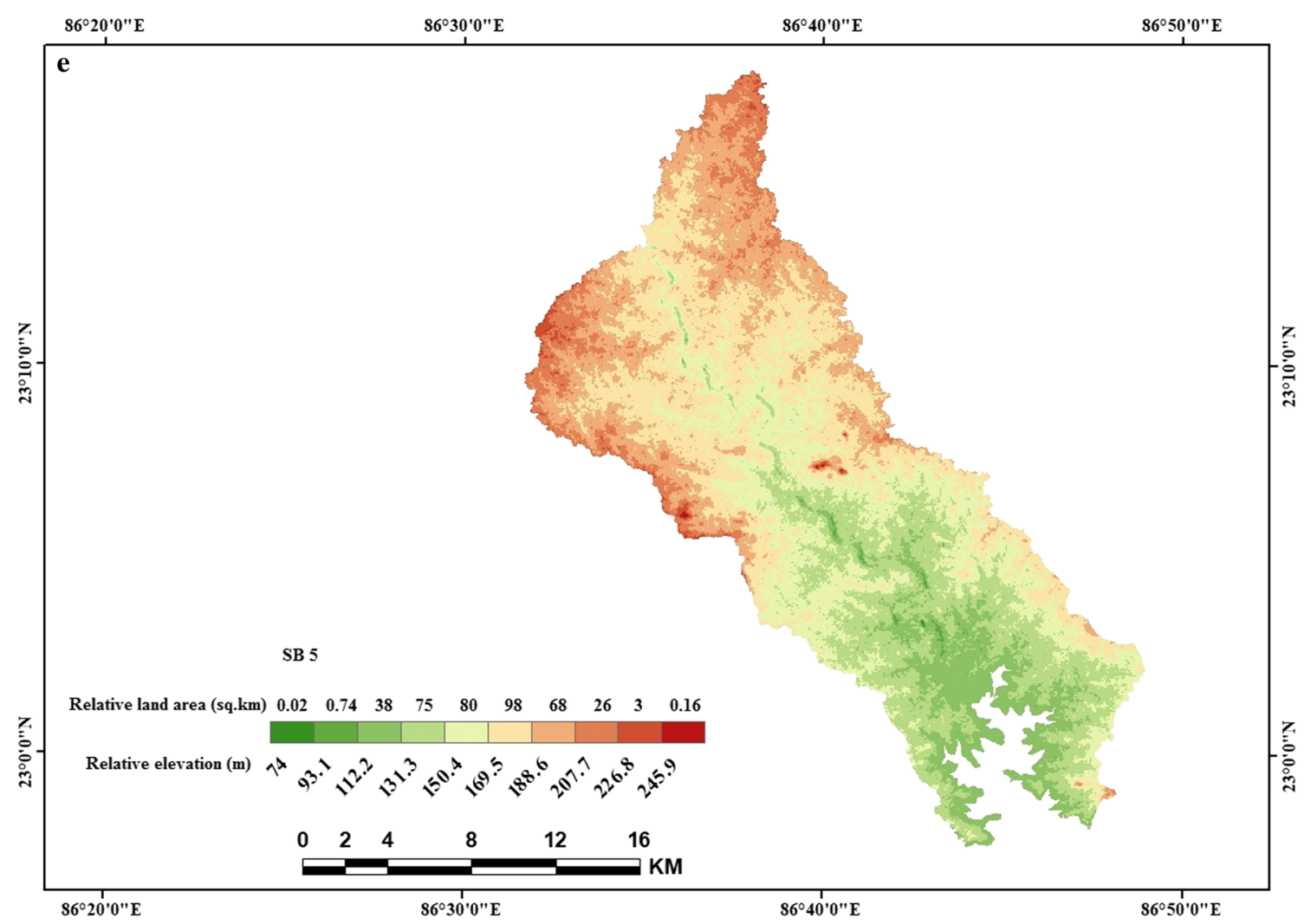

$86^{\circ} 10^{\prime} 0^{\prime \prime}$ E $\quad 86^{\circ} 20^{\prime} 0^{\prime \prime} \mathrm{E}$

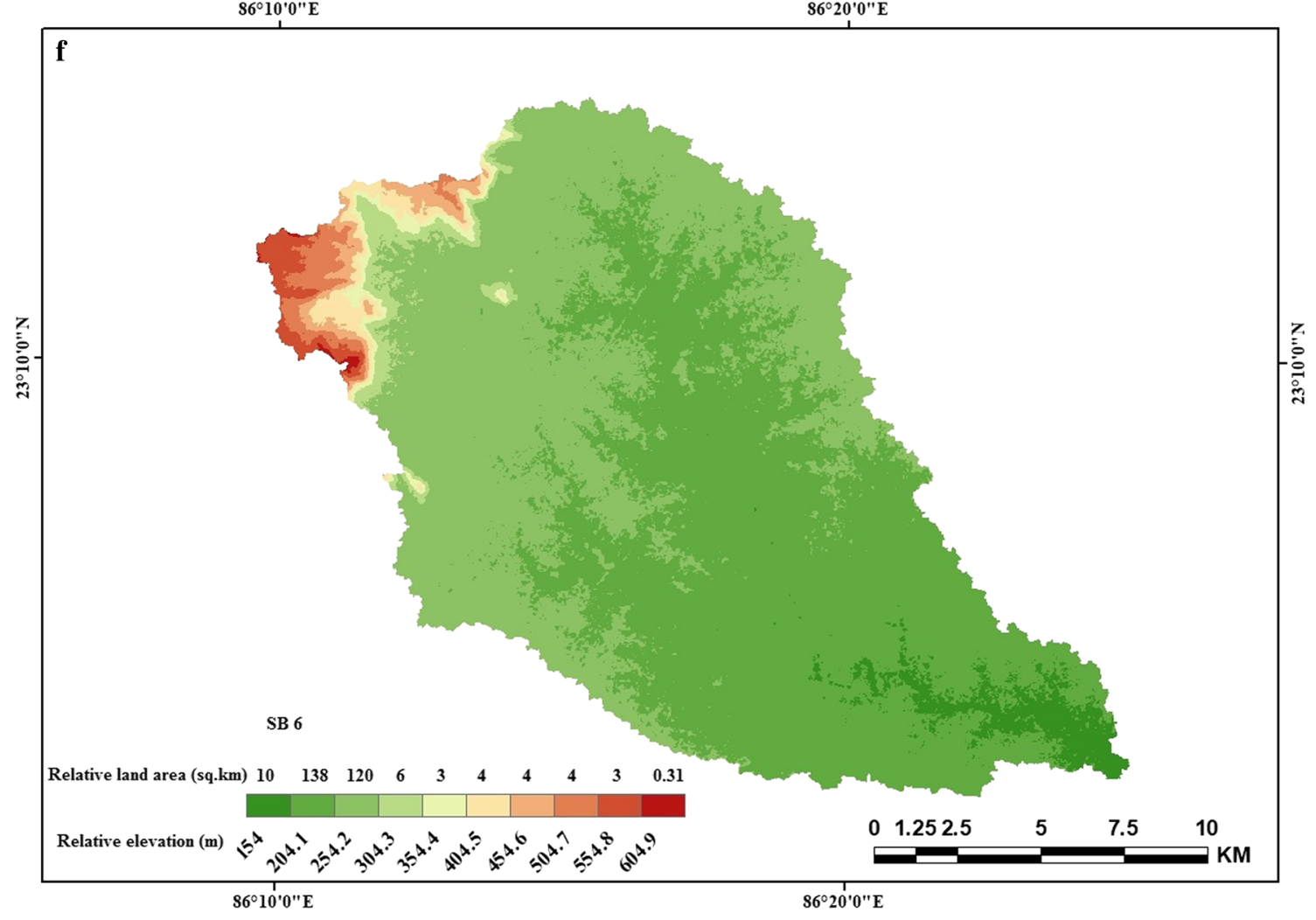

Fig. 10 (continued) 


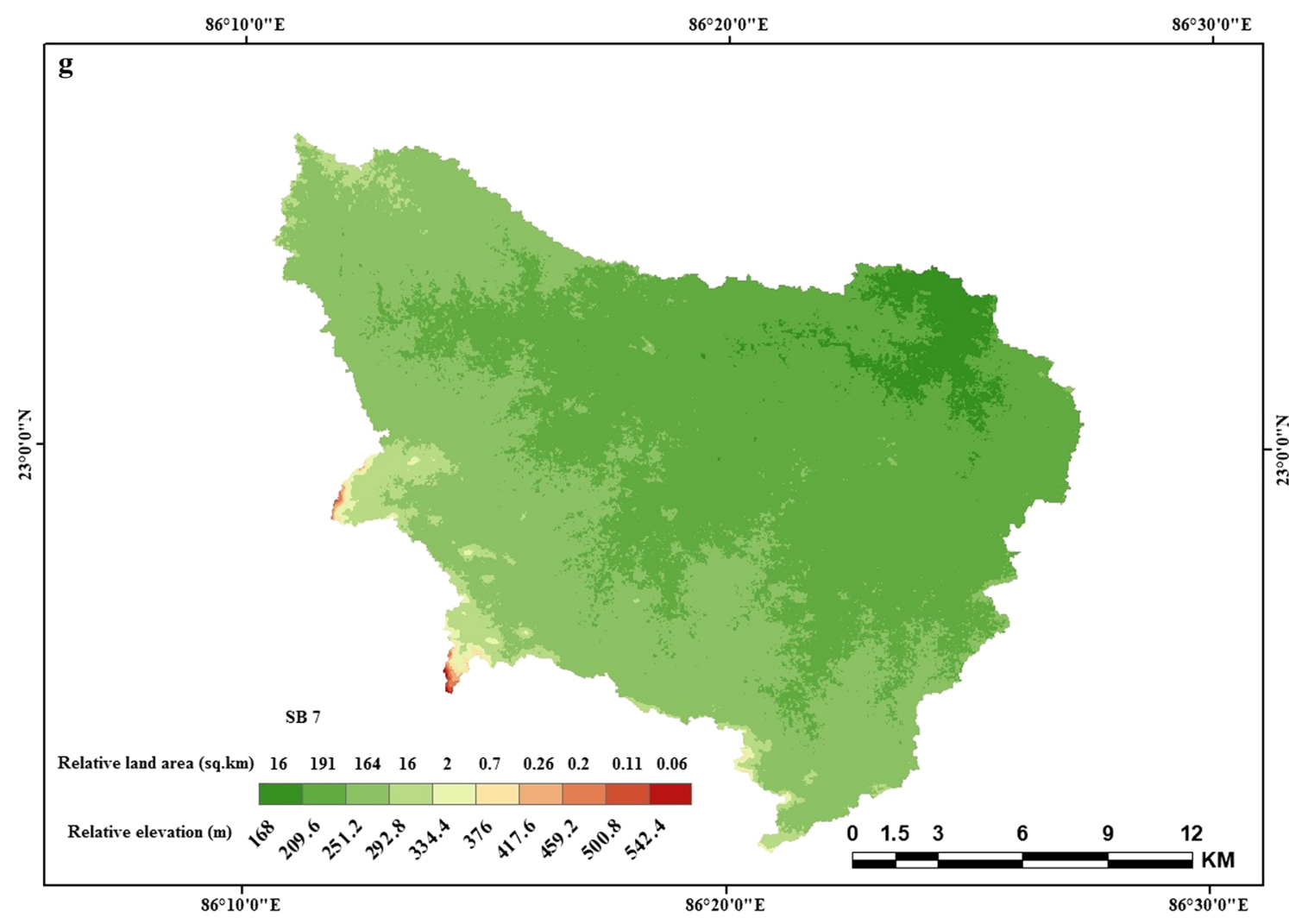

$86^{\circ} 30^{\prime} 0^{\prime \prime} \mathrm{E}$

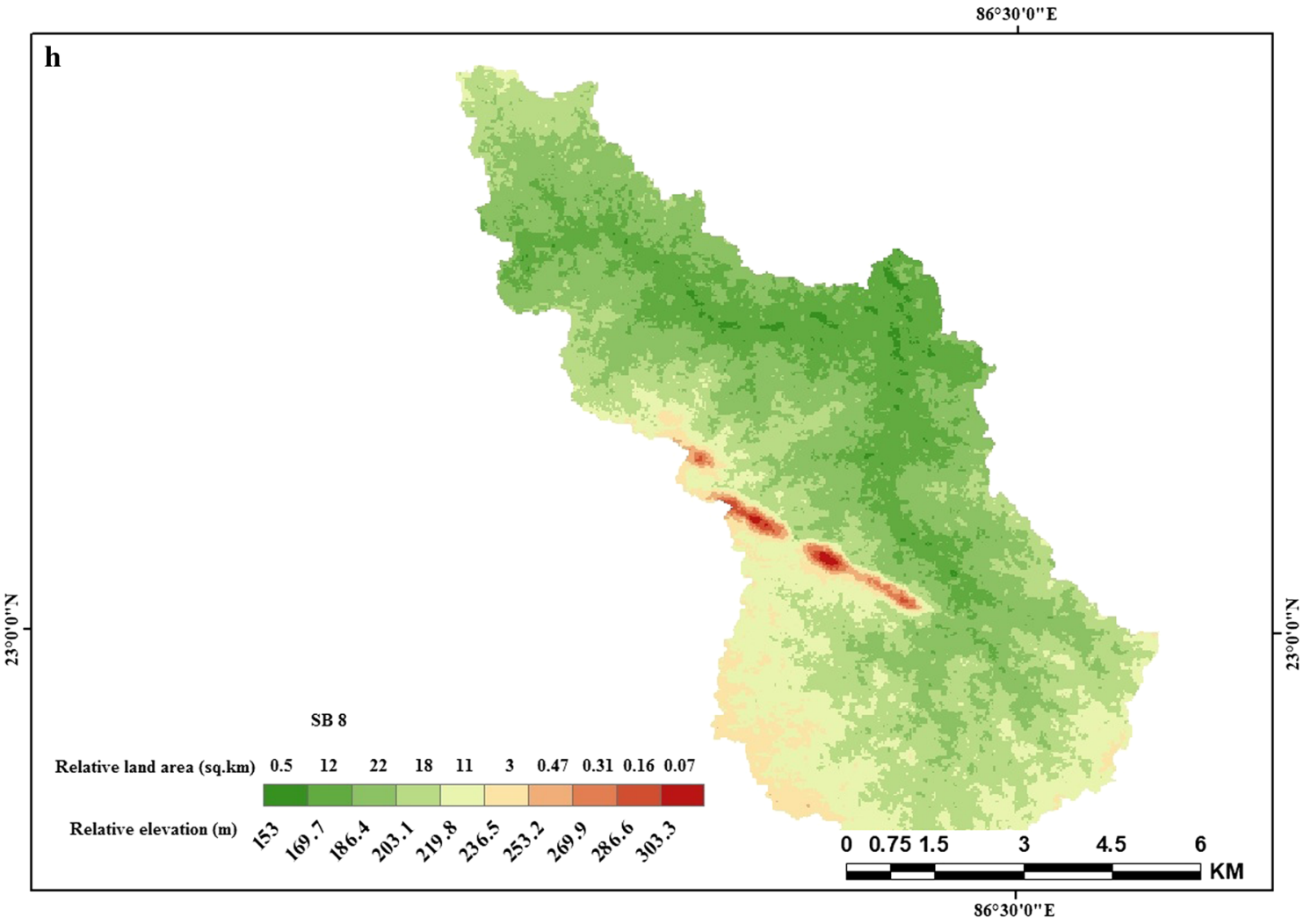

Fig. 10 (continued) 

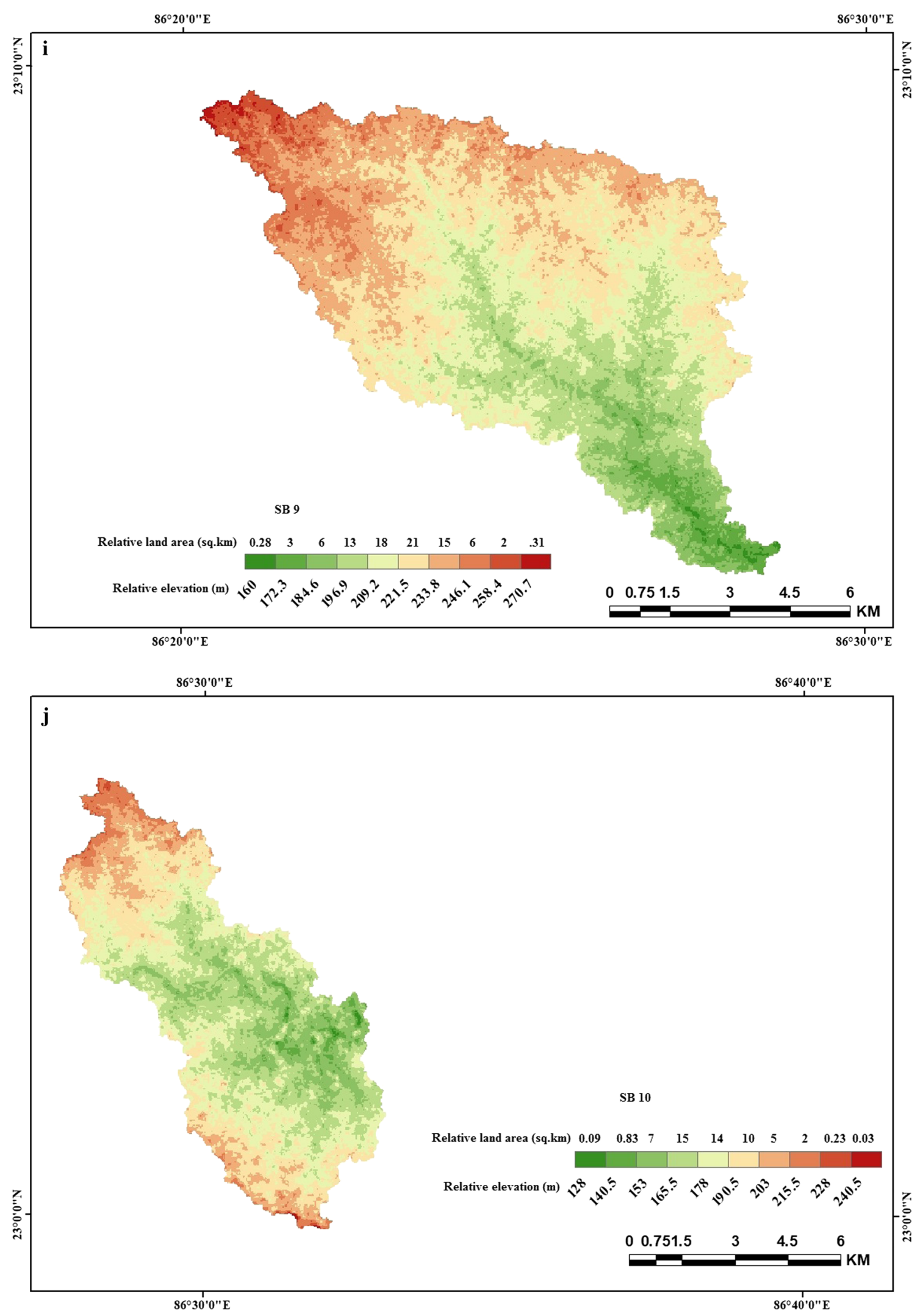

Fig. 10 (continued) 

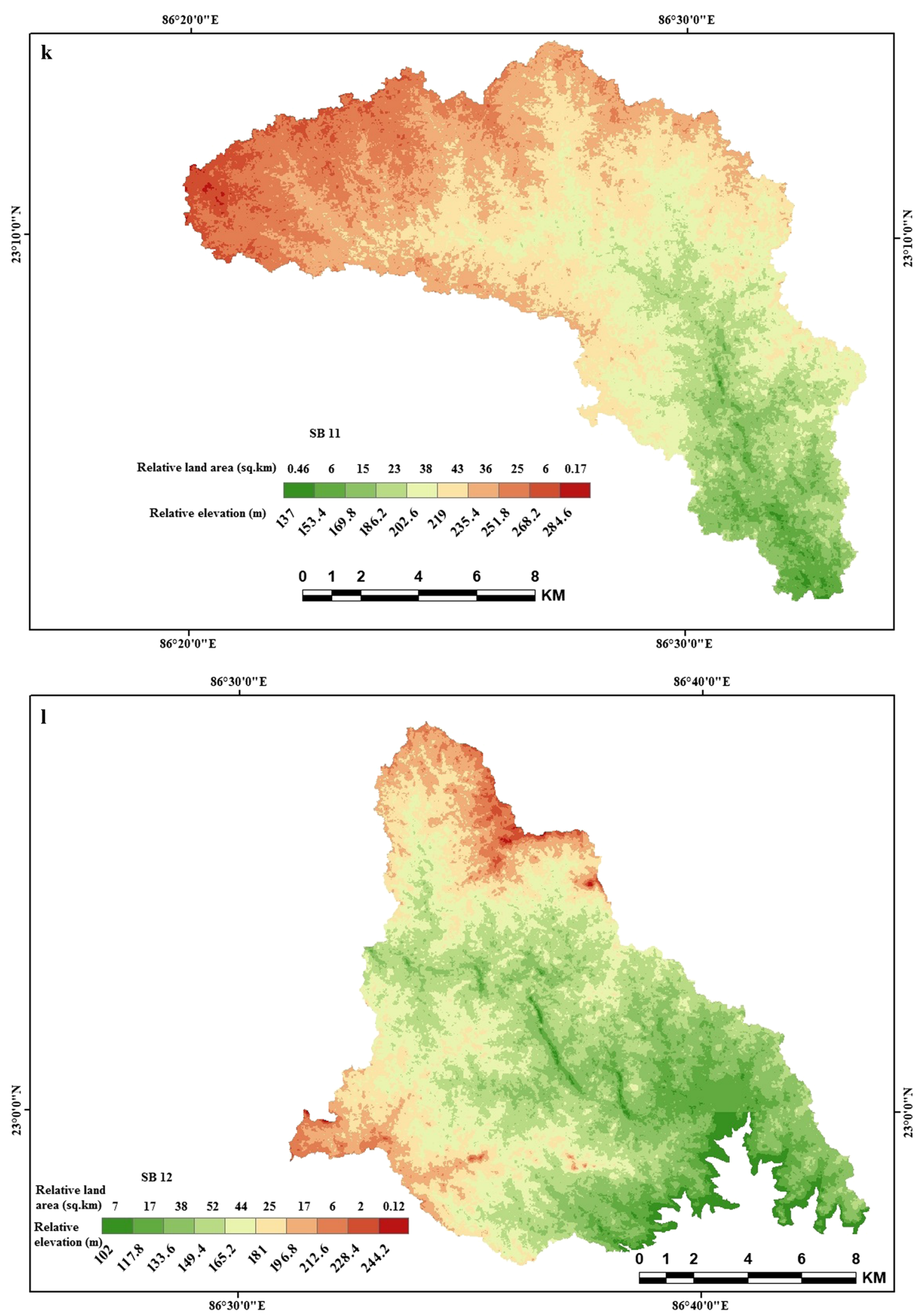

Fig. 10 (continued) 


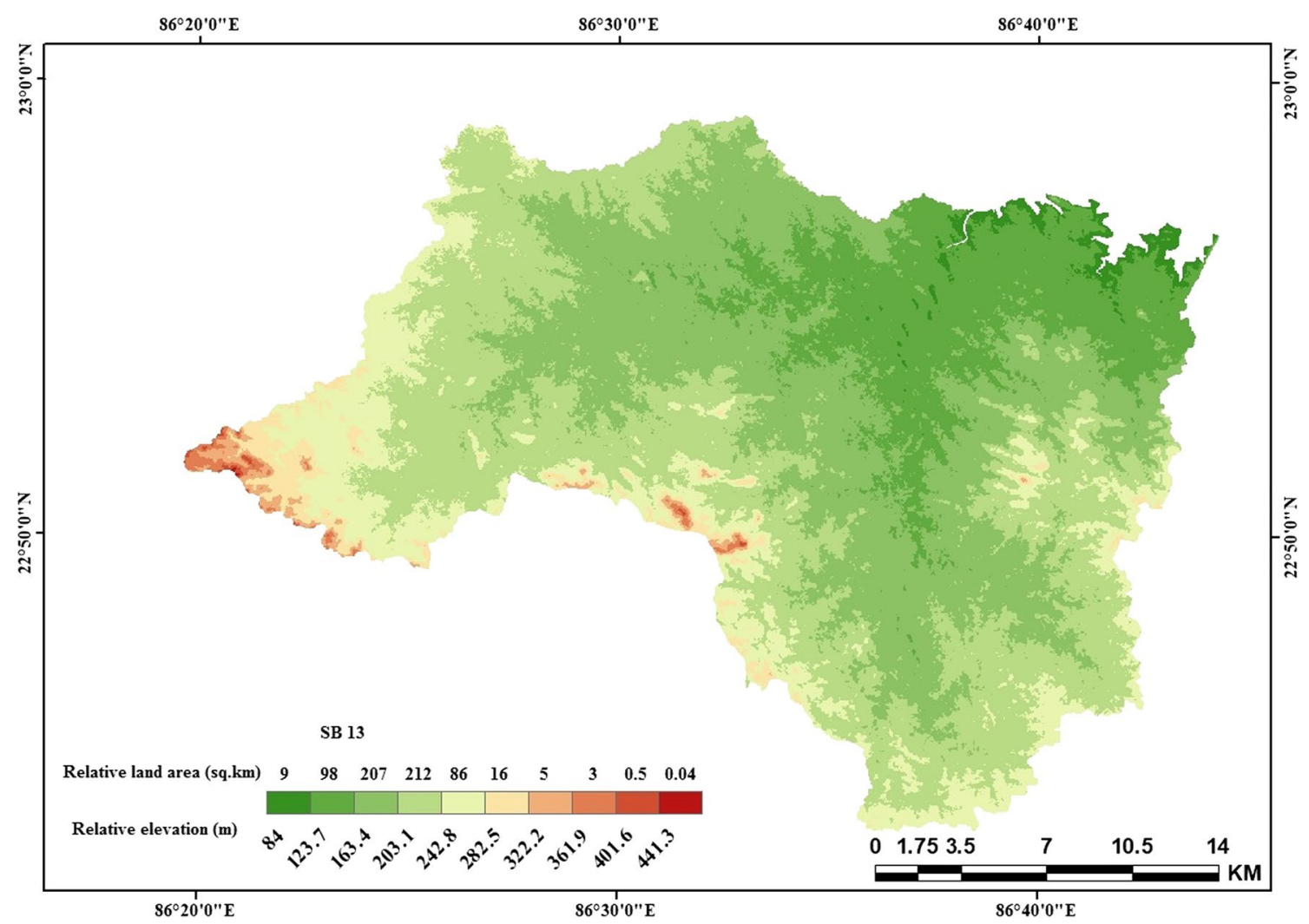

Fig. 10 (continued)

Table 12 Risk assessment of erosion susceptibility in study area

\begin{tabular}{lllllllll}
\hline SB & $H$ & $A$ & HI & $\Delta a$ & ga & Tu & Geological stage & Denudation rank \\
\hline 1 & 440 & 399 & 0.36 & 1.261603 & 0.748838 & 86 & Mature & Medium \\
2 & 443 & 200 & 0.4 & 1.234783 & 0.708347 & 90.35 & Mature & High \\
3 & 163 & 432 & 0.52 & 1.280488 & 0.728847 & 82.06 & Mature & Low \\
4 & 139 & 174 & 0.54 & 1.261261 & 0.803441 & 79.43 & Late youthful & Low \\
5 & 191 & 390 & 0.5 & 1.291829 & 0.85048 & 82.09 & Mature & Low \\
6 & 501 & 292 & 0.29 & 1.3 & 0.801088 & 86.35 & Old & Medium \\
7 & 416 & 390 & 0.29 & 1.288703 & 0.789026 & 84.35 & Old & Medium \\
8 & 167 & 69 & 0.4 & 1.355556 & 0.885961 & 87.28 & Mature & Medium \\
9 & 123 & 86 & 0.5 & 1.230769 & 0.748638 & 79.432 & Mature & Low \\
10 & 125 & 54 & 0.5 & 1.258065 & 0.721562 & 83.64 & Mature & Medium \\
11 & 164 & 192 & 0.512306 & 1.300885 & 0.766144 & 84.139 & Mature & Medium \\
12 & 158 & 207 & 0.43194 & 1.3 & 0.879455 & 83.32 & Mature & Medium \\
13 & 397 & 636 & 0.34 & 1.290381 & 1.117255 & 95.86 & Late mature & High \\
\hline
\end{tabular}

set-up and LULC but reached under late mature geological stage $(\mathrm{Hi}>0.35)$. SB3, 4,10 have low erosion risk rank or low denudation rate ( $\mathrm{tu}<83 \mathrm{t} / \mathrm{km}^{2} /$ year) due to the presence of high priority rank of morphometric, geology, geomorphic, slope and soil types but reached under the mature stage of geological setting $(\mathrm{Hi}>0.5)$. SB7, 8, 9 have medium risk rank or medium denudation rate (tu $<85 \mathrm{t} / \mathrm{km}^{2} /$ year) due to the presence of erosion-prone LULC patterns like cropland and laterite cover but having low basin priority rank and old geological stage $(\mathrm{Hi}<0.35)$. It is a point that denudation rate and geological stage of landform evolution do not have proportional relation, as well as priority rank of all themes, and do not match on compile basin prioritization at sub-basin level. Therefore, erosion susceptibility in the entire basin depends on every determinant themes not only morphometric parameters but also other associated parameters. On the 
Fig. 11 Hypsometric integral value in Kansai-Kumari reservoir catchment area

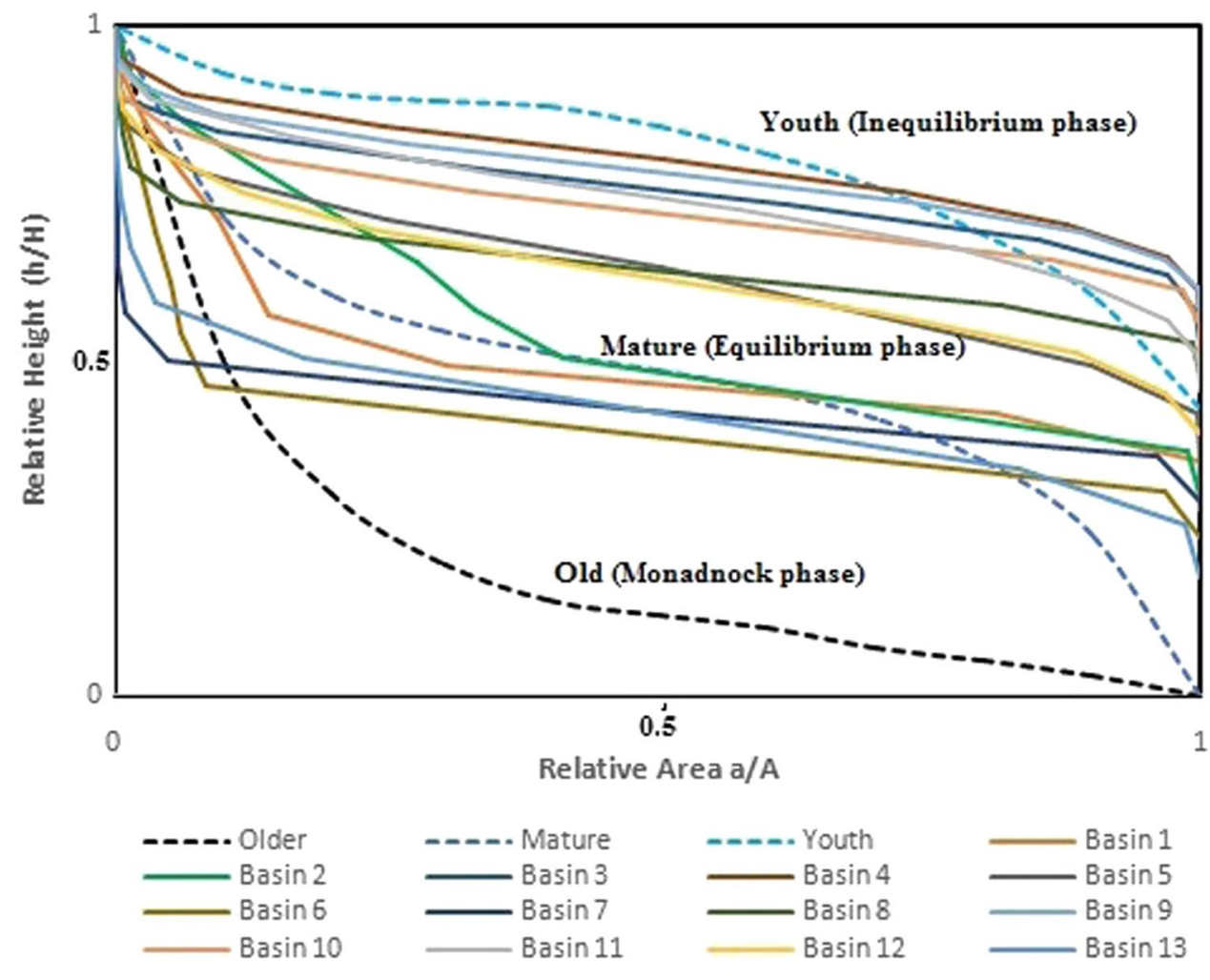

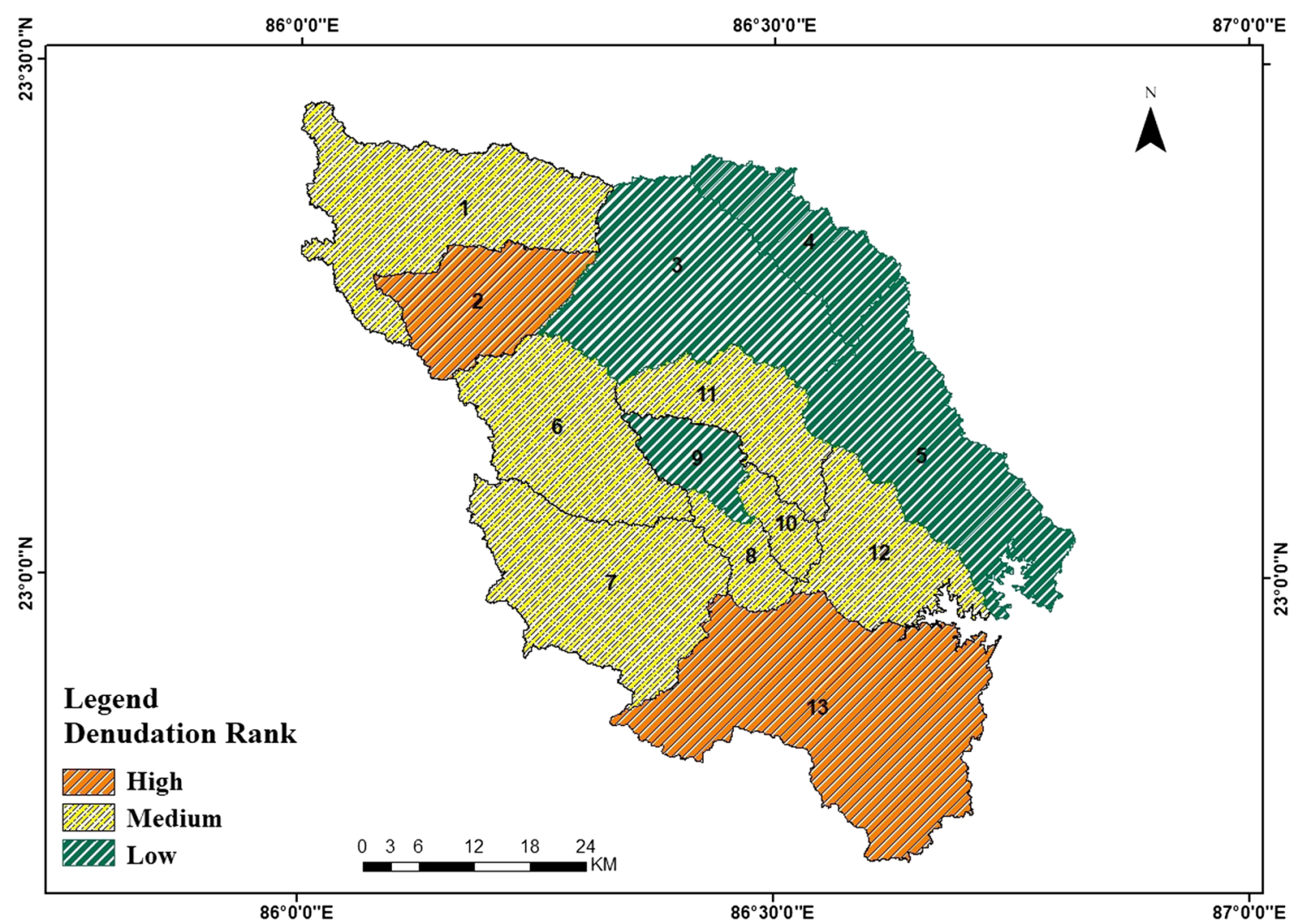

Fig. 12 Sub-basin-wise denudation rate in Kansai-Kumari reservoir catchment area 
other hand, basin prioritization and erosion risk assessment help in taking soil and water conservation measures with the following basin hydrological set-up and geomorphometric parameters.

Open Access This article is distributed under the terms of the Creative Commons Attribution 4.0 International License (http://creativeco mmons.org/licenses/by/4.0/), which permits unrestricted use, distribution, and reproduction in any medium, provided you give appropriate credit to the original author(s) and the source, provide a link to the Creative Commons license, and indicate if changes were made.

\section{References}

Aher PD, Adinarayana J, Gorantiwar SD (2013) Prioritization of watersheds using multi-criteria evaluation through fuzzy analytical hierarchy process. Agric Eng Int CIGR J 15(1):11-18

Altaf S, Meraj G, Romshoo SA (2014) Morphometry and land cover based multi-criteria analysis for assessing the soil erosion susceptibility of the western Himalayan watershed. Environ Monit Assess 186(12):8391-8412

Avena GC, Giuliano G, Lupia Palmieri E (1967) On the quantitative evaluation of the hierarchization and evolution of the fluvial networks. Boll Soc Geol Ital 86:781-796

Badar B, Romshoo SA, Khan MA (2013) Integrating biophysical and socioeconomic information for prioritizing watersheds in a Kashmir Himalayan lake: a remote sensing and GIS approach. Environ Monit Assess 185(8):6419-6445

Bahrami S (2013) Tectonic controls on the morphometry of alluvial fans around Danehkhoshk anticline, Zagros, Iran. Geomorphology 180:217-230

Biswas S, Sudhakar S, Desai VR (1999) Prioritisation of sub watersheds based on morphometric analysis of drainage basin: a remote sensing and GIS approach. J Indian Soc Remote Sens 27(3):155

Bonnet S, Crave A (2003) Landscape response to climate change: insights from experimental modeling and implications for tectonic versus climatic uplift of topography. Geology 31(2):123-126

Carlos GH, Ramon JB, Artemio C, de Luisa M (2012) A regional analysis of the effects of largest events on soil erosion. CATENA 95:85-90

Chandrashekar H, Lokesh KV, Sameena M, Ranganna G (2015) GIS-based morphometric analysis of two reservoir catchments of Arkavati River, Ramanagaram District, Karnataka. Aquat Procedia 4:1345-1353

Chauhan P, Chauniyal DD, Singh N, Tiwari RK (2016) Quantitative geo-morphometric and land cover-based micro-watershed prioritization in the Tons river basin of the lesser Himalaya. Environ Earth Sci 75(6):498

Chopra R, Dhiman RD, Sharma PK (2005) Morphometric analysis of sub-watersheds in Gurdaspur district, Punjab using remote sensing and GIS techniques. J Indian Soc Remote Sens 33(4):531

Ciccacci S, Fredi P, Lupia Palmieri E, Pugliese F (1980) Contributo dell'analisi geomorfica quantitativa alla valutazione dell'entità dell'erosione nei bacini fluviali. Boll Soc Geol It 99:455-516

Ciccacci SIRIO, Del Monte MAURIZIO, Marini ROBERTA (2003) Erosion and recent morphological change in a sample area of the upper Orcia River basin (Southern Tuscany, Italy). Geografia Fisica e Dinamica Quaternaria 26:97-109

Clarke JI (1996) Morphometry from maps. Essay in geomorphology. Elsevier, New York, pp. 235-274
Deepika B, Avinash K, Jayappa KS (2013) Integration of hydrological factors and demarcation of groundwater prospect zones: insights from remote sensing and GIS techniques. Environ Earth Sci 70(3):1319-1338

Della Seta M, Del Monte M, Fredi P, Palmieri EL (2007) Direct and indirect evaluation of denudation rates in Central Italy. CATENA 71(1):21-30

Farhan Y, Anaba O (2016) A remote sensing and GIS approach for prioritization of Wadi Shueib Mini Watersheds (Central Jordan) based on morphometric and soil erosion susceptibility analysis. J Geogr Inf Syst 8(01):1

Gajbhiye S (2015) Morphometric analysis of a Shakkar river catchment using RS and GIS. Int J u-and e-Service Sci Technol 8(2):11-24

Ganasri BP, Ramesh H (2016) Assessment of soil erosion by RUSLE model using remote sensing and GIS-A case study of Nethravathi Basin. Geosci Front 7(6):953-961

Gajbhiye S, Mishra SK, Pandey A (2014) Relationship between SCSCN and sediment yield. Appl Water Sci 4(4):363-370

Gajbhiye S, Mishra SK, Pandey A (2015a) Simplified sediment yield index model incorporating parameter CN. Arab J Geosci 8(4):1993-2004

Gajbhiye S, Sharma SK, Awasthi MK (2015b) Application of principal components analysis for interpretation and grouping of water quality parameters. Int J Hybrid Inf Technol 8(4):89-96

Gioia D, Martino C, Schiattarella M (2011) Long-to short-term denudation rates in the southern Apennines: geomorphological markers and chronological constraints. Geol Carpath 62(1):27-41

Gravelius H (1914) Grundriß der gesamten Gewasserkunde, Band 1: Flußkunde. Compendium of Hydrology, I, pp. 265-278

Horton RE (1932) Drainage-basin characteristics. Eos, Trans Am Geophys Union 13(1): 350-361

Horton RE (1945) Erosional development of streams and their drainage basins: hydrophysical approach to quantitative morphology. Bull Geo Soc Am 56:275-370

Jasrotia AS, Dhiman SD, Aggarwal SP (2002) Rainfall-runoff and soil erosion modeling using remote sensing and GIS technique-a case study of tons watershed. J Indian Soc Remote Sens 30(3):167-180

Javed A, Khanday MY, Ahmed R (2009) Prioritization of sub-watersheds based on morphometric and land use analysis using remote sensing and GIS techniques. J Indian Soc Remote Sens 37(2):261

Javed A, Khanday MY, Rais S (2011) Watershed prioritization using morphometric and land use/land cover parameters: a remote sensing and GIS based approach. J Geol Soc India 78(1):63

Kaliraj S, Chandrasekar N, Magesh NS (2015) Morphometric analysis of the River Thamirabarani sub-basin in Kanyakumari District, South west coast of Tamil Nadu, India, using remote sensing and GIS. Environ Earth Sci 73(11):7375-7401

Mahala A (2018) Soil erosion estimation using RUSLE and GIS techniques - a study of a plateau fringe region of tropical environment. Arab J Geosci 11(13):335

Malik MI, Bhat MS (2014) Integrated approach for prioritizing watersheds for management: a study of lidder catchment of kashmir himalayas. Environ Manag 54(6):1267-1287

Malik M, Bhat M, Kuchay NA (2011) Watershed based drainage morphometric analysis of Lidder catchment in Kashmir valley using Geographical Information System. Recent Res in Sci and Tech 3 (4): $118-126$

Martínez-Ramírez Á, Steinich B, Tuxpan J (2017) Morphometric and hypsometric analysis in the Tierra Nueva Basin, San Luis Potosí, México. Environ Earth Sci 76(12):444

Miller VC (1953) Quantitative geomorphic study of drainage basin characteristics in the Clinch Mountain area, Virginia and Tennessee. Technical report (Columbia University. Department of Geology), no. 3

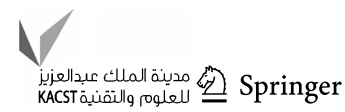


Meshram SG, Sharma SK (2017) Prioritization of watershed through morphometric parameters: a PCA-based approach. Appl Water Sci 7(3):1505-1519

Mukhopadhyay S (1992) Terrain analysis of river basin. Vora Publication, Mumbai

Nooka RK, Srivastava YK, Venkateshwara Rao V, Amminedu E, Murthy KSR (2005) Check dam positioning by prioritization of micro-watersheds using SYI model and morphometric analysisremote Sensing and GIS perspective. J Indian Soc Remote Sens 33(1):25-38

Patel DP, Dholakia MB, Naresh N, Srivastava PK (2012) Water harvesting structure positioning by using geo-visualization concept and prioritization of mini-watersheds through morphometric analysis in the Lower Tapi Basin. J Indian Soc Remote Sens 40(2):299-312

Patwary MAA, Champati PKR, Parvaiz I (2009) IRS-LISS-III and PAN data analysis for landslides susceptibility mapping using heuristic approach in active tectonic region of Himalaya. J Indian Soc Remote Sens 37:493-509

Perović V, Jakšić D, Jaramaz D, Koković N, Čakmak D, Mitrović M, Pavlović P (2018) Spatio-temporal analysis of land use/land cover change and its effects on soil erosion (Case study in the Oplenac wine-producing area, Serbia). Environ Monit Assess 190(11):675

Pike RJ, Wilson SE (1971) Elevation-relief ratio, hypsometric integral, and geomorphic area-altitude analysis. Geol Soc Am Bull 82(4):1079-1084

Rahaman AS, Ajeez AS, Aruchamy S, Jegankumar R (2015) Prioritization of sub watershed based on morphometric characteristics using fuzzy analytical hierarchy process and Geographical Information System-a study of Kallar Watershed. Tamil Nadu Aquat Procedia 4:1322-1330

Rashid I, Romshoo SA (2013) Impact of anthropogenic activities on water quality of Lidder River in Kashmir Himalayas. Environ Monit Assess 185(6):4705-4719

Romshoo SA, Bhat SA, Rashid I (2012) Geoinformatics for assessing the morphometric control on hydrological response at watershed scale in the Upper Indus Basin. J Earth Syst Sci 121(3):659-686

Rosenblatt P, Pinet PC, Thouvenot E (1994) Comparative hypsometric analysis of earth and venus. Geophys Res Lett 21(6):465-468
Sahaar AS (2013) Erosion mapping and sediment yield of the Kabul River Basin, Afghanistan; Fort Collins, Colorado

Schumm SA (1956) Evolution of drainage systems and slopes in badlands at Perth Amboy, New Jersey. Geol soc Am bull 67(5):597-646

Schumm SA, Hadley RF (1961) Progress in the application of landform analysis in studies of semiarid erosion (No. 437). [US Geological Survey]

Sharma SK, Tignath S, Gajbhiye S, Patil R (2013) Use of geographical information system in hypsometric analysis of Kanhiya Nala watershed. Int J Remote Sens Geosci 2(3):30-35

Sharma SK, Gajbhiye S, Nema RK, Tignath S (2015) Assessing vulnerability to soil erosion of a watershed of Narmada basin using remote sensing and GIS. Int J Sci Innov Eng Technol (1). ISBN:978-81-904760-6-5

Srivastava M, Joshi SP, Manhas RK, Singh L (2005) Biodiversity study in natural forests abandoned mine and ecorestored mine habitats of Mussoorie Hills. Bull Natl Inst Ecol 16:59-68

Sreedevi PD, Subrahmanyam K, Ahmed S (2005) The significance of morphometric analysis for obtaining groundwater potential zones in a structurally controlled terrain. Environ Geol 47(3):412-420

Strahler AN (1952) Dynamic basis of geomorphology. Bull Geol Soc Am 63:923-938

Strahler AN (1964) Part II. Quantitative geomorphology of drainage basins and channel networks. In: Handbook of applied hydrology. McGraw-Hill, New York, pp 4-39

Sujatha ER, Selvakumar R, Rajasimman B (2014) Watershed prioritization of Palar sub-watershed based on the morphometric and land use analysis. J Mt Sci 11(4):906-916

Tokunaga E (2000) Dimension of a channel network and space-filling properties of its basin. Trans Jpn Geom Union 21(4):431-499

Whipple KX (2009) The influence of climate on the tectonic evolution of mountain belts. Nat Geosci 2(2):97

Publisher's Note Springer Nature remains neutral with regard to jurisdictional claims in published maps and institutional affiliations. 